\title{
Broad bracketing for low probability events
}

\author{
Shereen J. Chaudhry ${ }^{1}$ (I) $\cdot$ Michael Hand $^{2} \cdot$ Howard Kunreuther $^{3}$
}

Accepted: 2 December 2020 / Published online: 29 January 2021

(C) The Author(s) 2021

\begin{abstract}
Individuals tend to underprepare for rare, catastrophic events because of biases in risk perception. A simple form of broad bracketing - presenting the cumulative probability of loss over a longer time horizon - has the potential to alleviate these barriers to accurate risk perception and increase protective actions such as purchasing flood insurance. However, it is an open question whether broad bracketing effects last over time: There is evidence that descriptive probability information is ignored when decisions are based on "experience" (repeatedly and in the face of feedback), which characterizes many protective decisions. Across six incentive-compatible experiments with high stakes, we find that the broad bracketing effect does not disappear or change size when decisions are made from experience. We also advance our understanding of the mechanisms underlying broad bracketing, finding that, while cumulative probability size is a strong driver of the effect, this is dampened for larger brackets leading people to be less sensitive to probability size.
\end{abstract}

Keywords Broad bracketing · Risk communication · Decisions from experience · Cumulative probabilities · Low-probability high-consequence events · Insurance

JEL Classification D81 - D91 · D01

This research was conducted while Dr. Chaudhry was employed as a postdoctoral research fellow at the Wharton Risk Management and Decision Processes Center, and while Dr. Hand was employed with the U.S. Department of Agriculture, Forest Service. The views expressed in this paper are the authors' and do not necessarily represent the views or positions of the U.S. Department of Agriculture or the U.S. General Services Administration.

\author{
Shereen J. Chaudhry \\ shereen.chaudhry@chicagobooth.edu \\ Michael Hand \\ michaels.hand@gsa.gov \\ Howard Kunreuther \\ kunreuth@wharton.upenn.edu
}

Extended author information available on the last page of the article 


\section{Introduction}

Companies and individuals often fail to protect themselves against rare, catastrophic events, such as flooding from natural disasters. Protective decisions can generally be thought of as choices that present two options, both with negative expected value: incur a certain cost (e.g., premium for purchasing flood insurance) or take a chance of incurring a much larger cost than the sure cost (e.g., a flood occurs causing one to pay out of pocket to repair flood damage to their house). In flood-prone areas in the United States, relatively few individuals have voluntarily purchased insurance, opting to take their chances with flood to their detriment. For example, the Federal Emergency Management Agency (FEMA) estimated that only 17\% of residents most affected by Hurricane Harvey had flood insurance (Long 2017). As a result, the U.S. federal government paid out over $\$ 1.2$ billion dollars in housing assistance (FEMA 2018). Thus, not taking protective actions harms flood victims and creates substantial negative externalities for governments.

Individuals' failure to engage in protective behaviors against rare catastrophes like flood likely stems from a combination of two judgment processes that defy the assumptions of expected utility theory. First, people often consider small probability events too rare to pay attention to, or below their threshold level of concern (Kunreuther 1996; Robinson and Botzen 2018; Slovic et al. 1977). Though in many cases people overweight small probabilities as suggested by prospect theory (Kahneman and Tversky 1979), in situations like natural disasters, where people receive feedback over time and update their beliefs about likelihoods of occurrence, people tend to underweight small probabilities (Barron and Erev 2003; Hertwig et al. 2004; Weber et al. 2004). Because the probability of events like natural disasters are often communicated in one-year increments (e.g., $1 \%$ annual chance), this may lead people to take their chances with the rare event rather than incur the upfront cost of protection without really considering what is optimal given their risk preferences.

Second, people exhibit myopia, or narrow bracketing, in their judgments and decisions - that is, people tend to focus on short time periods rather than acknowledging long-term exposure (Kahneman and Lovallo 1993; Read et al. 1999; Redelmeier and Tversky 1992). Thus, a homeowner may consider the annual $1 \%$ risk of a flood damage to their house to be too small to care about and not think about the fact that, because they plan on living in their house for 10 years, the risk they face is approximately a $10 \%$ chance of one or more floods over that period. Furthermore, even when people do consider the long-term, they tend to underestimate the cumulative effect of repeated exposure to risk (Doyle 1997; Fuller et al. 2004; Keller et al. 2006; Knäuper et al. 2005; Linville et al. 2015; Shaklee and Fischhoff 1990; Slovic et al. 1978).

Previous research suggests that directly countering the narrow bracketing tendency by using broad bracketing might lead people to behave differently and to opt more often for the protective action. Broad bracketing involves conveying cumulative information about the distribution of possible outcomes of a gamble over a certain broad period of time. For example, when converted to a 50-year bracket, a $1 \%$ annual chance of flood translates to the following: $60 \%$ chance of no flood, $31 \%$ chance of one flood, $8 \%$ chance of two floods, $1 \%$ chance of three or more floods. Researchers found that providing the broad bracket distribution for choices between a sure loss $(-\$ 4)$ and a pure loss gamble played 50 times $(-\$ 0.10,90 \%$; $-\$ 0.50,10 \%)$ led people to avoid the 
gamble and choose the sure loss more often (Webb and Shu 2017). This setup is analogous to protective decisions and so we will use the terms protective decisions and pure loss choices interchangeably, as well as the terms protective action and sure loss.

We suggest that applying broad bracketing to the context of protective decisions will lead more people to opt for the protective action. In this investigation, we implement and test whether this effect holds for a simpler, more scalable version of broad bracketing: We present only the cumulative loss probability, or the cumulative probability of one or more losses over a given time horizon (e.g., 39\% chance of one or more floods over 50 years). Two studies have examined the effect of such cumulative loss probabilities on risk perceptions (De La Maza et al. 2019; Keller et al. 2006), but no prior work has examined the impact on making choices between options (for a review see Visschers et al. 2009).

Central to our investigation is addressing the following concern: While the evidence from Webb and Shu (2017) suggests that broad bracketing will result in increased protective action, there is evidence that its effect will diminish over time due to people's experiences. Experience is a key feature of protective decisions, which often must be made monthly or annually and after learning whether the event has occurred or not (e.g., annually purchasing flood insurance, regularly clearing drains, or checking that one's sump pump is operational). Prior to a disaster, individuals ignore the possibility (optimism), then reverse and give it heightened attention after the disaster occurs (availability), and finally, after time passes without another loss, they forget the impact the disaster had and revert to ignoring its possibility again (amnesia; Meyer and Kunreuther 2017). Research has shown that, even if people obtain objective probability information about disasters, they begin to ignore this descriptive information (which the broad bracket is) in favor of risk perceptions based on their own experience (Jessup et al. 2008; Lejarraga and Gonzalez 2011; Newell et al. 2016; Rakow et al. 2008; Yechiam and Busemeyer 2006).

Neither the Webb and Shu article nor other research on broad bracketing (Benartzi and Thaler 1999; Hardin and Looney 2012; Looney and Hardin 2009; Thaler et al. 1997) has demonstrated that broad bracketing would be robust to experience. We are the first to examine whether broad bracketing can shift people strongly and consistently toward protective behavior when decisions are made repeatedly in the face of feedback. The results have implications for whether or not broad bracketing could serve as a useful tool for risk communication regarding protective decisions.

Past research has also left unknown the mechanism underlying broad bracketing by always confounding two features in the broad bracket manipulation: probability size and time horizon length. As a result, it is unclear whether people only respond to the larger probabilities or whether they also consider the time horizon over which the probabilities are calculated. We expect that, while larger probabilities will lead more people to attend to and respond to the broad bracket, longer time horizons will moderate that response. For example, we expect that presenting people with a $10 \%$ chance of flood over 10 years will lead to more protective behavior than presenting them with a $10 \%$ chance over 200 years. Utilizing our more scalable version of broad bracketing allows us to isolate the key attributes of the framing technique (probability size and time horizon length) and uncover the separate roles played by these two components in the broad bracket effect. These findings provide insight into the judgment processes underlying broad bracketing and serve as guidance for how to structure a broad bracket intervention for risk communication. 
The next section reviews previous work on risk perception and broad bracketing and discusses the contribution of our study. In Section 3, we provide an overview of the experiments. In Sections 4-9, we describe the rationale, methods, and results for Studies 1-6. Section 10 discusses the implications of our findings and suggests future directions.

\section{Risk perception and decisions from experience}

People tend to underweight small probabilities when learning about probabilities through experience rather than through explicit presentation or description (Barron and Erev 2003; Hertwig et al. 2004; Weber et al. 2004). People also sometimes engage in an editing process wherein they ignore events with probabilities below their threshold level of concern (Kunreuther 1996; Robinson and Botzen 2018; Slovic et al. 1977). Because individuals often assess the probability of an event, like a natural disaster, using their own experiences and because these events tend to be rare, this may explain why people choose not prepare for future disasters (Kunreuther et al. 1978; McClelland et al. 1993; Meyer and Kunreuther 2017). The upfront cost may not seem worth it given the infrequent observation of occurrence.

Even if a person faces a one-time risk that is very small, the chances of a negative event occurring increases with repeated exposure to that risk. In an extreme example, a $1 \%$ annual chance of a flood translates to approximately a $0.0027 \%$ daily chance of a flood. On any given day the miniscule chance of flooding likely falls below the threshold of concern for most people. But a $1 \%$ annual chance of a flood also translates to a $26 \%$ chance of at least one flood over 30 years, the term of a typical mortgage. If the broad bracket (i.e., 30-year time horizon) more closely aligns with how people make residential location and home purchase decisions than the narrow bracket (i.e., one year or one day), then the broad-bracket probability information may be more relevant for aligning protective actions to risk preferences.

Evidence suggests people tend to narrowly bracket their judgments and decisions, thinking only about the near term (Kahneman and Lovallo 1993; Read et al. 1999; Redelmeier and Tversky 1992). This myopic behavior is reinforced by the external choice context, which often frames risks over a small time period. For example, flood risks are normally presented in terms of the annual chance of a disaster, rather than a time horizon that is likely to be relevant for residential location decisions.

People also underappreciate how risks accumulate over time because of the complexity of the calculation (Doyle 1997; Fuller et al. 2004; Keller et al. 2006; Knäuper et al. 2005; Linville et al. 2015; Shaklee and Fischhoff 1990; Slovic et al. 1978). Thus, even when asked to consider a larger bracket, unless people are given explicit probabilities, they tend to underestimate how much aggregation over time or repeated exposure affects the probabilities (Redelmeier and Tversky 1992).

\subsection{Broad bracketing and cumulative probabilities}

Given people's tendencies to underweight low probability events, to narrowly bracket their decisions, and to underappreciate the aggregation of risk over time, explicitly presenting cumulative probabilities over a longer span of time could help people 
consider rare, catastrophic events as within their threshold level of concern. Broadly bracketed information about the risk of a catastrophic loss may reduce risk seeking (preference for the pure loss gamble) and encourage protective actions (preference for the sure loss) like purchasing insurance. While previous work on broad bracketing involved presenting the full distribution of outcomes, we present only a single number representing the probability of at least one loss within that time, i.e., the cumulative loss probability, which is most relevant for considering losses from natural disasters. The risk perception literature has documented people's difficulty in recognizing and understanding cumulative risk (Doyle 1997; Fuller et al. 2004; Keller et al. 2006; Knäuper et al. 2005; Linville et al. 2015; Shaklee and Fischhoff 1990; Slovic et al. 1978), and two papers have examined the effect of cumulative loss probabilities on judgments (De La Maza et al. 2019; Keller et al. 2006), but no work has examined how explicitly presenting cumulative risk can be helpful in changing behavior.

Hypothesis 1 (H1). Compared to narrow bracketing, broad bracketing operationalized as the "cumulative loss probability" will increase the likelihood that people will choose a sure loss over a pure loss gamble.

\subsection{Broad bracketing in the face of repetition and feedback}

Many real-world decisions, especially those involving protective actions, require people to make decisions repeatedly. In other words, the decisions cannot be locked in for the period of the broad bracket and, furthermore, the decision maker cannot avoid receiving feedback over time. For instance, homeowners decide annually whether to purchase a one-year flood insurance policy, even if they plan to live in their homes for several years. This decision is then followed by feedback about whether or not a flood has actually occurred during that year.

Because evidence suggests that broad bracketing will not hold up in the context of experience with repetition and feedback, this is an important feature to test. Research suggests that decisions makers tend to lean more on information they get from experience and less on the explicit descriptions of event probabilities they are given (with broad bracketing falling into the description category; Jessup et al. 2008; Lejarraga and Gonzalez 2011; Newell et al. 2016; Rakow et al. 2008; Yechiam and Busemeyer 2006). For low probability events, people may begin to ignore the broadly bracketed information over time and switch from sure loss (protective action) to the pure loss gamble (no protective action).

This is the first investigation to examine whether broad bracketing lasts and is robust to experience. Most empirical research on broad bracketing has focused on decisions in which participants make a single decision that is locked in for the period of the broad bracket (Benartzi and Thaler 1999; Gneezy and Potters 1997; Redelmeier and Tversky 1992; Webb and Shu 2017). Studies with repeated decisions and feedback have not explicitly examined the effect of experience or asked whether it interacted with broad bracketing (Hardin and Looney 2012; Looney and Hardin 2009). These designs also did not involve rare events, which are ones most likely to yield large deviations between experience-based and description-based decisions over time. 
To formulate our hypothesis about the interaction of broad bracketing with experience, we account for two strong patterns of behavior that have been observed in decisions from experience: the recency effect and the gambler's fallacy (Croson and Sundali 2005; Plonsky et al. 2015; Yin et al. 2016). The recency effect leads to excessive focus on recent experiences (Barron and Yechiam 2009; Hertwig et al. 2004; Hogarth and Einhorn 1992) or those experiences most available in memory (Tversky and Kahneman 1973). In a flood context, the recency effect suggests that a homeowner is likely to be more risk averse and engage in protective behavior in the immediate aftermath of a flood; as time passes without the occurrence of another flood, the emotional effects of the experience fade and the homeowner may decide to take their chances and drop their insurance. Behavior depends on events in the decision maker's most recent memories, which changes over time. Recent empirical research has found some evidence that flood insurance purchasing behavior among Florida homeowners is consistent with this effect (Dumm et al. 2020).

The gambler's fallacy is due to a mistaken understanding of what randomness looks like: People assume that events that have just occurred are less likely to occur again next period but are more likely to occur as time passes since their last occurrence (Ayton and Fischer 2004; Jarvik 1951; Kahneman and Tversky 1972). The gambler's fallacy suggests that a homeowner would be less likely to purchase insurance immediately after experiencing a flood but would start to worry that another flood is "due" to happen and invest in protection as time passes without the occurrence of a flood.

Both the recency effect and gambler's fallacy imply that experience-based choices exhibit some baseline variation over time. To account for the possible influence of the recency effect or gambler's fallacy on broad bracketing, we consider two timeframes: the "immediate" behavioral response following the occurrence of a negative event and the "delayed" behavioral response over time.

Hypothesis 2 (H2). The effect of broad bracketing on choice of the sure loss will not be eliminated with experience (i.e., repetition and feedback). In particular, the effect will not be eliminated either as time passes without the occurrence of a loss as a result of the recency effect (H2A), or in the immediate aftermath of a loss as the result of the gambler's fallacy $(\mathrm{H} 2 \mathrm{~B})$.

\subsection{Judgment processes behind broad bracketing}

There is no guidance in the literature on how best to construct a broad bracket because very little work has explored the underlying mechanism. It is currently unclear whether only the probability of loss drives the broad bracket effect or whether decision makers also attend to the size of the bracket (which in this case corresponds to the length of the time horizon). That is, we do not know whether people respond the same to a $26 \%$ chance of at least one flood over 30 years as they would to a $26 \%$ chance over 200 years, despite the former representing a risk that is almost seven times larger (i.e., a $1 \%$ per year compared to a $0.15 \%$ per year).

Recent research suggests, but does not explicitly test, that people ignore the time horizon and attend primarily to the probability size. People weight losses more when receiving broadly bracketed information about a pure loss gamble, and this leads to 
increased risk aversion and more frequent selection of the sure loss (Webb and Shu 2017). The authors further show that the framing technique does not operate by getting people to focus more on the number of times they will be exposed to a risk. If people focus primarily on probability size, then a longer time horizon (i.e., a broader bracket) will have a greater impact on protective behavior simply because the probability of a loss appears larger. Thus, people would be more likely to engage in protective behavior when they learn that there is a $26 \%$ chance of at least one flood over 30 years than when they learn there is a $5 \%$ chance over 5 years, despite the fact that the underlying likelihood of flood is the same.

Hypothesis 3 (H3). For a pure loss gamble, the larger the bracket that is used for communicating the cumulative loss probability, the more likely people are to select the sure loss.

If people also pay attention to the time horizon, they might discount larger cumulative probabilities if those probabilities are associated with longer time horizons. People are somewhat (but not fully) aware of how probabilities of outcomes change with multiple exposures to a risky event, like a gamble (e.g., Redelmeier and Tversky 1992; Samuelson 1963). This means that people might respond more strongly to a $26 \%$ chance of at least one flood over 30 years than to a $26 \%$ chance over 200 years. Thus, lengthening the bracket, i.e., increasing both the cumulative probability and time horizon, as suggested in $\mathrm{H} 3$ might not necessarily increase protective behavior. Instead, the length of the time horizon may moderate the impact of cumulative probability size on behavior:

Hypothesis 4 (H4). The greater the cumulative probability displayed, the more likely people will be to select the sure loss (H4A), but for a given cumulative probability, the larger the bracket associated with that probability, the less likely people will be to select the sure loss (H4A).

\section{Overview of current work}

This paper investigates whether the effect of broad bracketing on choices in the loss domain is robust to experience - i.e., repeated decision making with feedback — which is a critical feature for it to function as a robust risk communication tool. Furthermore, we examine a simpler, more scalable form of the broad bracket, which allows us to shed light on the mechanism. In particular, we investigate how the size of the cumulative probability and the length of the time horizon moderate the broad bracket effect, and doing so provides guidance to risk communicators for how to structure a broad bracket in their messages.

We conducted six web-based experiments with real payoffs that ask study participants to make choices between accepting a certain small loss or accepting a chance of a much larger loss. All six experiments share the same basic experimental design, which is based on an incentive-compatible mechanism from a previous paper on insurance decisions (Kunreuther and Michel-Kerjan 2015). Studies 1-5 test whether broad bracketing increases the proportion of people who take protective action and whether that effect is 
robust to experience. Study 3 examines whether the effect of broad bracketing is impacted by allowing earnings from previous choices to accumulate over rounds and whether it is robust to increasing the cost of insurance. Study 4 tests whether the results from the previous studies generalize to participants who actually live in highly flood-prone areas, and whether the broad bracket effect is robust to simultaneous presentation with the narrow bracket. Study 5 examines whether the effect of broad bracketing increases with longer time horizons, and Study 6 investigates the relative contribution of probability size and time horizon length to the broad bracket effect. All data, power analyses, and preregistrations are available on the Open Science Framework (OSF) at: https://osf.io/mejf5/.

\subsection{General study set up and procedures}

Choices in the studies mimicked the structure of insurance decisions, where there is a small premium a person can incur to avoid a much larger loss with a low probability (1\% chance per round). The survey was designed using the online survey platform Qualtrics. After reading the instructions and completing a comprehension check, participants began a 15-round phase of the experiment (except for Study 6, which was a single round). At the beginning of each study individuals received an endowment and in each round had to select between two options: (1) a sure loss (the insurance premium) or (2) a gamble with a $1 \%$ chance of losing a portion of the endowment (pure loss gamble) in any round. Participants knew they would make this decision multiple times, but were unaware of the precise number (15 rounds in Studies 1-5, 1 round in Study 6), knowing only that it would be fewer than 25 . We did this to avoid different behavior in the last round of the experiment (i.e., round 15), a common occurrence in multi-period experiments.

After each round, participants were given feedback about whether or not the gamble resulted in a loss, regardless of which option they had chosen. In Studies 1, 2, and 4 the $\$ 95$ endowment was restored to the initial level so that the financial impact of decisions in previous rounds would have no impact on their decision in the current round. In Studies 3 and 5 the endowment from the previous round was carried over to the next round (e.g., a lower endowment if the participant experienced an uninsured loss). The exact wording of the study scenarios can be found in Appendix B.

\subsection{Participant recruitment and power analysis}

We recruited a planned number of participants meeting required criteria for each study from Amazon's Mechanical Turk (MTurk; except for Study 3 in which we collected participants through a Qualtrics panel). Summary statistics for participants in each of the studies are shown in Table A0 in Appendix A. Statistical power to detect relevant effect sizes for parameters of interest was estimated for each study using a simulationbased procedure (conducted in Stata/IC version 14.2, code available upon request). Simulations created 500 replicate estimates of the relevant statistical model for a given planned number of participants and effect size. Statistical power was defined as the percent of replicates where a true effect was detected and could rule out a null effect with $95 \%$ confidence. The power analysis for all studies assumed a baseline rate of choice of sure loss of 0.617 (the baseline rate of choice of a sure loss from Kunreuther and Michel-Kerjan (2015), who used a similar experimental setup). We powered our 
studies to detect between a 6-9 percentage point difference for the main effect of broad bracketing, and between $0.2-4.0$ percentage point interaction between the broad bracket and our experience variables. See Table A1 in the appendix for results of the power analyses, including planned sample sizes and minimum detectible effects for Studies $1-6$.

\subsection{Payments}

Participants were endowed with a large amount of money (\$95), so the decisions would be treated as important and consequential; Study 1 (abstract context) expressed the endowment in dollars, while Studies 2-6 (flood insurance context) expressed the endowment in "talers," a fictional currency $(1000$ talers $=\$ 1)$ so participants would consider larger numeric amounts as in a real flood insurance decision.

To keep the experimental costs reasonable, one in every 100 participants was selected at random to play the experiment for real money. Earlier studies demonstrated that this strategy is just as effective in motivating behavior as paying all participants (Charness et al. 2016; Clot et al. 2018). As in Kunreuther and Michel-Kerjan (2015) participants played for real money by randomly being assigned a number between 0 and 99 displayed on the screen at the beginning and end of the experiment. They were given a specific future date and time of the Florida Pick-2 Lottery (http://www. flalottery.com/pick2) and told that if their number was chosen at that time they would be paid based on their decisions from a random round of the experiment. The number of the random round was displayed on the screen at the end of the experiment.

\section{Study 1: Abstract context}

The first experiment determines whether presenting the cumulative loss probability decreases risk-seeking in the loss domain in the context of abstract gambles (H1) as has been shown for the standard form of broad bracketing (Webb and Shu 2017), and whether this change is robust to experience, i.e., repetition and feedback (H2). In each round participants simply choose either a small sure loss or a pure loss gamble that has a low probability of a large loss and a high probability of no loss. We hypothesize that the broad bracket will increase the proportion of people selecting the sure loss and that this will not change substantially across rounds.

\subsection{Methods}

Procedure At the beginning of each round, each individual was endowed with $\$ 95$ and had to select between two options: (1) a sure loss of $\$ 0.45$ (sure loss) or (2) a gamble with a $1 \%$ chance of losing $\$ 45$ (pure loss gamble) in any round. They received feedback about the gamble after each round. At the beginning of each round, the $\$ 95$ was restored to the initial level so that the financial impact of decisions in previous rounds would have no impact on their decision in the current round.

Design The experimental design was a 2 (bracket size: 1-play, 30-play) $\times 3$ (occurrence of loss: no loss, early loss, late loss) between-subjects design so that participants were 
randomly assigned to one of six conditions. Half the participants learned the 1-play likelihood of a loss occurring from selecting the gamble (1\%), while the other half learned the 30-play likelihood of at least one loss occurring (26\%). One third of the participants were assigned to witness a loss in round 4 (early-loss group), one third in round 11 (late-loss group), and the last third would not observe any losses (no-loss group) whether or not they had selected the small sure loss in that round.

Measures After reading the initial instructions, but before beginning the first round of the experiment, participants had to correctly answer three comprehension check questions in order to proceed (see Appendix B2 for more detail). We assessed risk preferences using two measures: one self-reported and one choice-based. The selfreported measure was as follows: "How do you see yourself: Are you generally a person who likes to take risks or do you try to avoid taking risks?" [sliding scale: $0=$ not at all willing to take risks to $10=$ very willing to take risks] (Dohmen et al. 2011). The choice-based measure was adapted from Gneezy and Potters (1997): We endowed participants with $\$ 0.50$ and gave them an opportunity to invest in an option with a $50 \%$ chance of succeeding and a $50 \%$ chance of failing. If the option succeeded, they would receive 2.5 times the amount they invested, but if it failed, they would lose the amount they invested. Participants had to decide how much of the 50 cents they wanted to invest in the option (in 1-cent increments). Participants also answered questions about their age, gender, income, education, employment status, and political identity. ${ }^{1}$ At the end of the experiment, a random round was selected, and participants were told whether the option succeeded or failed and how much money they earned from their decisions. They would be paid based on this round if they were selected from the Florida Pick-2 Lottery.

Participants A total of 1076 participants completed the study and passed the comprehension check $\left(56 \%\right.$ female, $\mathrm{M}_{\mathrm{age}}=36$ years, $\left.\mathrm{SD}=11.2\right)$.

Payment Participants were paid on average \$1.07 (range: \$0.50-\$1.75), which included a bonus based on their answer to the Gneezy-Potters investment task. Five people chosen at random were each paid $\$ 94.55$ based on their choices in the experiment.

\subsection{Results and discussion}

Each participant made 15 rounds of choices with respect to opting for a sure loss or engaging in a pure loss gamble. Table 1 summarizes the results of random-effects linear panel (1076 participants by 15 rounds) regressions with heteroscedasticity-consistent

\footnotetext{
${ }^{1}$ To check whether behavior and perceived risk mirrored each other, after rounds $1,4,11$, and 15, participants indicated their perception of the likelihood that a loss would occur in the next round. We only asked this question four times to reduce decision fatigue. We chose rounds 1 and 15 to assess participants' initial beliefs without experience and their final beliefs. We included rounds 4 and 11 to examine the immediate effect of witnessing a loss on participants' beliefs. The question was asked after participants learned the outcome for that round and was posed as follows: "How likely do you feel it is that the lottery next period will result in a loss?" [sliding scale: $0=$ extremely unlikely to $10=$ extremely likely]. Analysis of this variable available upon request.
} 


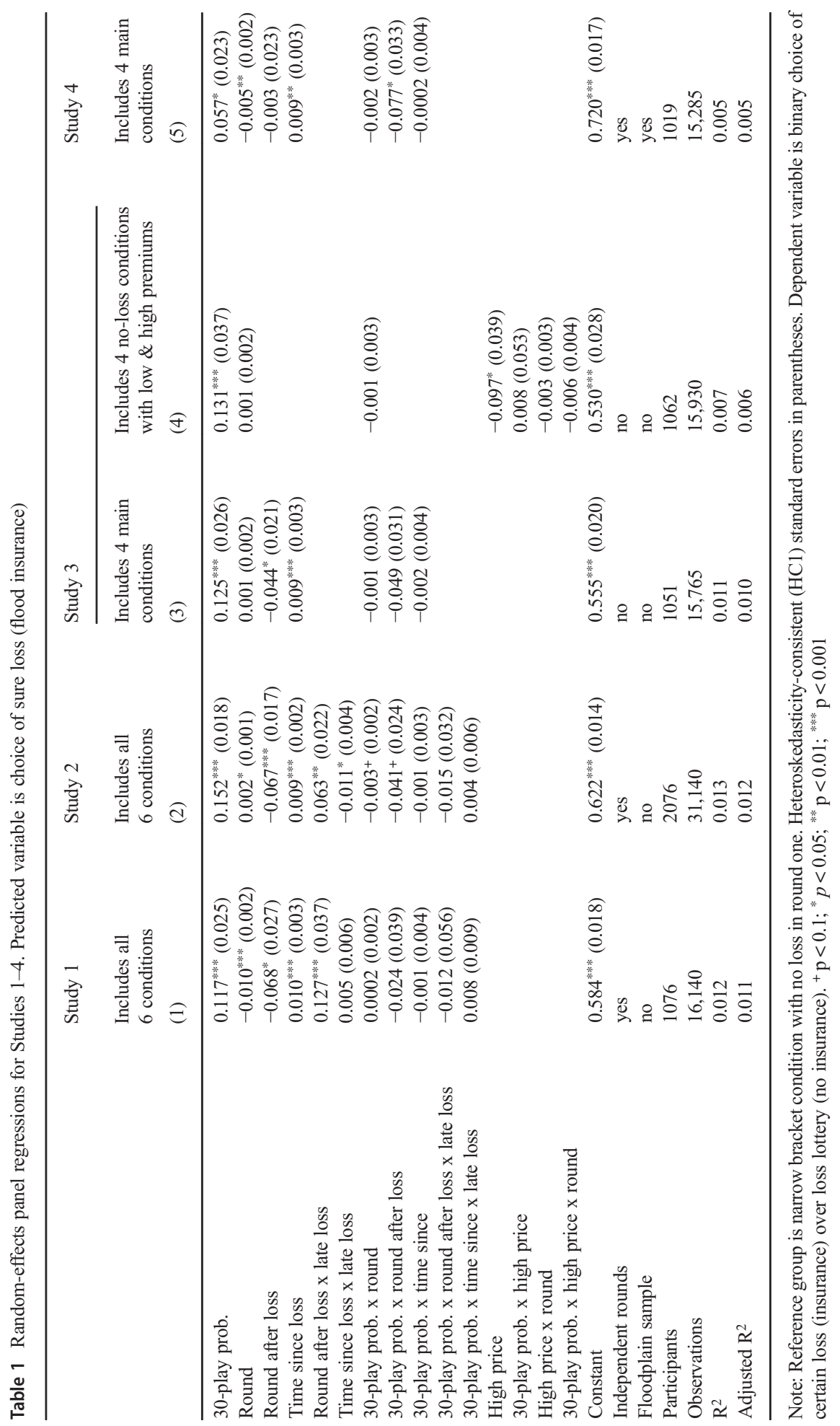


standard errors (MacKinnon and White 1985) for Studies 1-4, with results for Study 1 in column $1 .^{2}$ The predicted variable is the percentage of people choosing the sure loss. The reference or baseline group in the regression is the no-loss 1-play condition in round one with the average proportion selecting the sure loss in this group represented by the constant term. Coefficients capture deviations from this level. Fig. 1 displays results for Studies 1-4 (panels a-d). Each panel displays the proportion of participants selecting the sure loss across all 15 rounds of the experiment for the no-loss and earlyloss conditions. ${ }^{3}$ Study 1 results can be found in panel a.

Broad bracket effect (H1) As predicted by H1, those who were given the 30-play cumulative loss probability in the pure loss gamble were more likely to select the sure loss than those who learned the 1-play probability. The Table 1, column 1 coefficient on the broad bracket condition indicator ("30-play prob.") reveals that participants in the broad bracket condition were 11.7 percentage points more likely to select the sure loss in the first round and prior to experiencing a loss compared to those in the narrow bracket condition. This effect holds when controlling for sex, age, education, income, and risk tolerance (Table A2, column 1).

Interaction with experience (H2) To determine whether the broad bracket effect changed across rounds and was influenced by witnessing or experiencing a loss (H2), we included three additional variables in the regression ("round," "round after loss," and "time since loss") to determine whether they interacted with the variable representing the broad bracket effect. The "round" variable is specified as a linear trend variable that takes on values of the rounds (i.e., 2-15), with round one as the reference. Its coefficient describes the average marginal effect of the occurrence of a round on the selection of the sure loss, that is, the effect that experience (or time) has on choices. ${ }^{4}$ In order to capture further elements of the recency effect and gambler's fallacy for people who witnessed a loss, we included variables to separately capture behavior change in the round immediately after a loss and behavior change over time after the loss. "Round after loss" is an indicator variable equal to 1 for choices of early-loss participants in round five and for choices of late-loss participants in round twelve (and equal to 0 otherwise). "Time since loss" is specified as a linear trend variable that is always equal to 0 for participants in the no-loss conditions, but that is equal to values between 1 to 11 for the early-loss and late-loss conditions depending on how many rounds have

\footnotetext{
${ }^{2}$ In the estimates that follow, the variance-covariance matrix of the estimates is modified to account for heteroscedasticity under general conditions with a degrees-of-freedom correction (referred to as the HC1 method, MacKinnon and White 1985). In this case, because the number of respondents and observations is relatively large, using $\mathrm{HC} 1$ standard errors (instead of the random-effects least-squares standard errors) and the choice of $\mathrm{HC} 1$ modification does not have a noticeable effect on inference and the qualitative results.

3 The conditions with a late loss shock are included in the regression analysis, but the figures exclude them for ease of visual comparison with later studies that only include an early loss shock.

4 Alternative specifications could include "round" and "time since loss" as vectors of dummy variables, or with non-linear terms. A dummy-variable model would avoid the choice of a functional form for the rounds variables as there is no particular theoretical reason to include these variables as linear trends. Appendix Table A3 presents two versions of the Study 1 results with rounds included as dummy variables; the conclusions about broad bracketing do not qualitatively change in these models, and there does not appear to be strong evidence that a linear trend specification is inappropriate.
} 
a

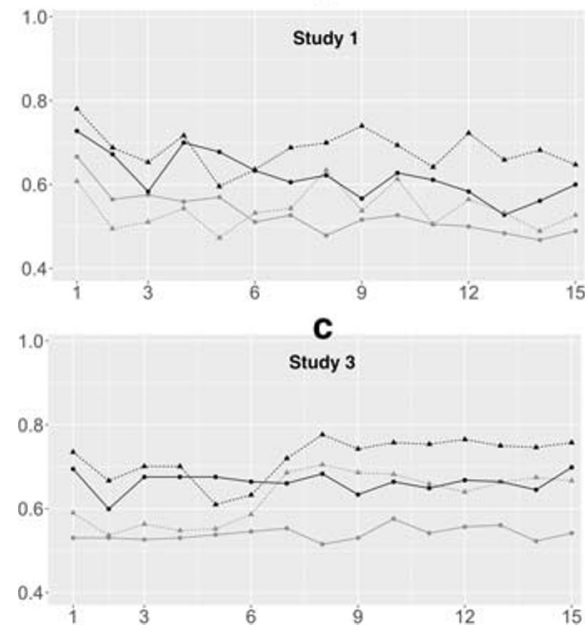

b

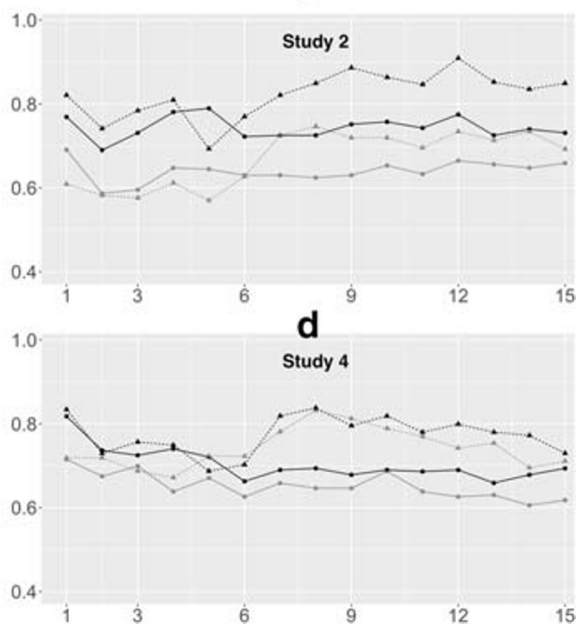

Fig. 1 Proportion of participants selecting the sure loss (purchasing flood insurance) in each round for Studies 1-4 (panels a-d). The $\mathrm{x}$-axis indicates the round number. The same four conditions are shown for each study: narrow-bracket no-loss (solid grey with circle markers - - ) , 30-year broad-bracket no-loss (solid black with circle markers - - - ), narrow-bracket early-loss (dashed gray with triangle markers - - _ - ), and 30-year broad-bracket early-loss (dashed black with triangle markers - - $\mathbf{\Delta}$ - -). The broad bracket conditions are represented by black lines, while the narrow bracket conditions are represented by gray lines. Solid lines with circle markers indicate conditions in which no loss occurred, while dashed lines with triangle markers represent conditions in which a loss occurred at the end of round 4

occurred since the gamble resulted in a loss. For instance, for the early loss group, the value of that variable would be 1 for round five, 2 for round six, and so on.

The "round" variable shows a slight recency effect: Over time more people switched from the sure loss to the gamble (1 percentage point per round as shown in row 2). However, this round effect did not differ for people given the cumulative loss probability ("30-play prob. x round"), so the broad bracket effect was neither eliminated nor did it change in size for the no-loss conditions across rounds, or for the pre-loss rounds of the loss conditions. That is, while experience did affect purchasing behavior, it did so similarly for those with the narrow and broad brackets. More specifically, the extent to which the broad bracket led to a higher proportion of participants purchasing insurance than the narrow bracket was consistent across time.

The delayed effect of a loss ("time since loss") was the same for the early- and lateloss conditions and was consistent with elimination of the recency effect discussed above: After a loss, participants were no longer likely to switch to the gamble as time passed. The immediate effect of a loss ("round after loss" and "round after loss x late loss") was different for the early- and late-loss groups, with people in the former group being less likely to choose the sure loss in the round immediately after a loss and those in the latter group being more likely. While this may be an interesting difference driven by the different timings of the loss, exploring it is beyond the scope of this investigation. While witnessing a loss did cause significant changes in choice that were both immediate ("round after loss" and "round after loss x late loss") and delayed ("time since loss"), none of these changes interacted with the broad bracket. Thus, the effect of 
a loss did not undo or even mitigate the impact the broad bracket on selection of the sure loss. These results hold with the inclusion of controls (Table A2, column 1).

\section{Study 2: Flood insurance context}

Study 2 enriched the experimental setup to reflect a risk communication environment, as recent research suggests that participants exhibit behavior that differs in relevant and important ways when choices are framed neutrally rather than in a particular context (see Jaspersen 2016 for a review). For example, participants show more risk aversion when making decisions about insurance than when making context-free decisions for the same risk (Hershey and Schoemaker 1980; Lypny 1993). To map onto the structure of Study 1, we chose a setting in which participants decide whether or not to purchase flood insurance by paying a premium to avoid a large loss.

\subsection{Methods}

Procedure The procedure for this experiment was identical to that of Study 1, except that the scenario now incorporated a flood insurance context with endowments expressed in the fictional taler currency. Participants were told in each round that they needed to decide if they should buy flood insurance at a cost of 450 talers to protect their house from a flood that could cause 45,000 talers in damage. They would learn at the end of every year whether or not a flood occurred and see a summary of their assets given their insurance decision.

Design The experimental design was the same as in Study 1: It was a 2 (bracket size: 1year, 30-year) $\times 3$ (loss occurrence: no loss, early loss, late loss) between-subjects design so that participants were randomly assigned to one of six conditions. ${ }^{5}$ In this study, the narrow bracket conditions displayed the annual flood probability, while the broad bracket conditions displayed the likelihood of experiencing at least one flood over a 30-year time horizon.

Measures As in Study 1, we included comprehension check questions, two methods to assess risk preferences, and four subjective probability assessments. We also included questions eliciting personal experience with past flooding and purchasing flood insurance to use as control variables in our regressions. The exact wording of the scenario and these measures are detailed in Appendix B.

Participants A total of 2076 participants completed the study and passed the comprehension check ( $45 \%$ female, $\mathrm{M}_{\mathrm{age}}=35.9$ years, $\left.\mathrm{SD}=11.1\right)$.

\footnotetext{
${ }_{5}^{5}$ We also included a manipulation that tested the effect of a policy relevant feature of real-world flood insurance decisions: the designation of a person's house as being located within a FEMA-named Special Flood Hazard Area, generally considered higher risk zones. We expected this dichotomous naming convention would have an impact on decisions. This line of inquiry was pursued for its policy relevance but was not germane to our investigation of broad bracketing. Importantly, there was no detectable impact of this information, so we collapsed across those conditions in our investigation of the hypotheses at hand.
} 
Payment Participants were paid on average \$1.09 (range: \$0.51-\$1.75), which included a bonus based on their answer to the Gneezy-Potters investment task. Additionally, 18 participants were randomly chosen to be paid based on their choices - 15 of them received $\$ 94.55$, while the other three received $\$ 95$.

\subsection{Results and discussion}

Table 1, column 2 displays the results of Study 2, where the predicted variable is the percentage of people purchasing insurance. The reference condition in the regression is the no-flood 1-year condition in round one, and the average proportion purchasing insurance in this group is represented by the constant term. Fig. 1b displays the proportion of participants purchasing insurance across all 15 rounds of the experiment for the conditions with no flood damage and those with an early flood loss.

Broad bracket effect (H1) As in Study 1, broad bracketing increased the proportion of participants purchasing flood insurance, thus supporting H1. Participants shown the cumulative loss probability over 30 years were 15.2 percentage points more likely to purchase insurance in the first round and prior to experiencing a loss than those who saw the 1-year probability of a flood. This effect holds when controlling for real-life flood experience as well as sex, age, education, income, and risk tolerance (Table A2, column 2).

Interaction with experience $(\mathrm{H} 2)$ We used the same variables to examine the effect of experience as we did for Study 1 ("round," "round after loss," "time since loss", "round after loss x late loss", "time since x late loss"). The broad bracket ("30-year prob.") did not interact with any of these experience variables, thus supporting H2. These results hold with the inclusion of controls listed above (Table A2, column 2).

\section{Study 3: Non-independent decisions}

One limitation of Studies 1 and 2 is that each of the rounds was independent from previous ones so that participants were shielded from having a choice in an early round permanently ruin their chances to earn a large bonus in the experiment. This treatment may have reduced the potential for experience-based effects and is not as reflective of real-world decisions, where a past outcome impacts future choices. An additional consideration is that, in Studies 1 and 2, the insurance premium was set equal to the expected value of the loss, but in real life, the price is usually much higher than the expected loss (i.e. the actuarially fair premium) due to loading costs. Thus, Study 3 extends our investigation by making rounds nonindependent, that is, by structuring the experiment so that earnings carry over across all 15 rounds, and by testing whether price interacts with the broad bracket effect.

\subsection{Methods}

Procedure The procedure for this experiment was similar to Study 2, except that earnings carried across rounds (i.e., the endowment did not reset with each round in 
the event of an uninsured loss). The initial endowment remained the same (\$95) but the house value was reduced to 80,000 talers, the savings account was increased to 15,000 talers, and potential damage from a flood was reduced to 35,000 so earnings could be cumulated across rounds. At the end of each round, participants were provided with the value of their total assets based on their insurance decision and whether or not a flood had occurred during the round. Participants' total earnings were summarized at the end of the experiment.

Design The experimental design was a 2 (bracket size: 1-year, 30-year) $\times 2$ (loss occurrence: no-loss, early-loss) between-subjects design. The cost of insurance in these conditions was the actuarially fair premium (350 talers per year). To examine the impact of the insurance premium on behavior, we included two additional no-loss conditions in which the premium was much higher (1000 talers per year): 1-year high price and 30-year high price. Participants were randomly assigned to one of these six conditions.

Measures We included the same questions as in Study 2 and additional measures designed to assess participants' ability to calculate probabilities across different time periods, the perceived relevance/usefulness of the cumulative probability information, and the preferred time period over which each participant would like to know the cumulative probability. The details of these measures can be found in the Appendix B.

Participants A total of 1587 participants completed the study and passed the comprehension check ( $45 \%$ female, $\mathrm{M}_{\mathrm{age}}=35.9$ years, $\mathrm{SD}=11.9$ ).

Payment Participants were paid on average \$1.95 (range: \$1-\$2). In addition, 20 participants were randomly chosen to receive payment based on their choices in the experiment, receiving between $\$ 80$ and $\$ 90$.

\subsection{Results and discussion}

Broad bracket effect (H1) For the main analyses testing H1 and H2 (Table 1, column 3), we include only the four main conditions in which the price of insurance was set to the actuarially fair premium of 350 talers $(N=1051)$. Fig. 1c displays the proportion of participants purchasing insurance in these four conditions. We find a significantly positive impact of the broad bracket ("30play prob.") on choice in the direction predicted: Participants were 12.5 percentage points more likely to purchase insurance in the first round (prior to experiencing a loss) than those who saw the 1-year probability. This effect holds when controlling for real-life flood experience as well as sex, age, education, income, and risk tolerance (Table A2, column 3).

Interaction with experience (H2) The broad bracket did not interact with any of the experience variables ("round," "round after loss," "time since loss"). These results hold with the inclusion of controls (Table A2, column 3). 
Price effects To examine whether price interacted with the broad bracket, we conducted an analysis that compared the 1-year and 30-year no-loss conditions from the main analysis with the two additional conditions in which the price of insurance was set to 1000 talers $(N=1062$; Table 1 , column 4). Though we found that the increased price led to an overall drop in insurance purchasing by about 9.7 percentage points ("High price"), we found no interaction between price and the broad bracket ("30-play prob. X high price"). We also did not find any interaction between price and either round ("High price X round") or round and the broad bracket ("30-play prob. X high price X round").

Thus, we found that allowing earnings to carry across rounds did not qualitatively or quantitatively affect the main broad bracketing effect nor did it lead to an interaction of the broad bracket with experience, offering confirming evidence for $\mathrm{H} 1$ and $\mathrm{H} 2$. These effects hold when controlling for real-life flood experience as well as sex, age, education, income, and risk tolerance (Table A2, column 4).

\section{Study 4: Disaster-prone sample}

In Study 4, we extend our investigation in three ways. First, we collect a sample of participants living in highly flood-prone areas. We target US counties where people are likely to have more experience with both flooding and flood insurance. Second, we test whether giving participants both the narrow and broad brackets eliminates the effect of broad bracketing. One concern with the broad bracket is that it operates by skewing people's preferences, making them behave more risk aversely than is consistent with their underlying risk preferences. This suggests that decision makers primarily care about the narrow bracket, and only use the broad bracket to make inferences about the narrow bracket, which they do imperfectly. If this is true, then presenting both versions would completely eliminate the broad bracket effect because decision makers would ignore the broad bracket. However, if the foregoing explanation does not entirely account for the effect-i.e., if people still find the broad bracket informative - then the effect will not be eliminated entirely. In cases where people anticipate making multiple decisions over an extended time period, we expect that decision makers will still find the broadly bracketed information useful and respond to it.

Third, we test whether participants are sensitive to whether the time frame determining the bracket is "relevant." People might pay attention to the 30-year bracket because it seems like a reasonable time horizon given that participants are told they will play up to 25 rounds. We examine whether participants ignore the broad bracket information if the time frame is extremely large (100 years and 200 years).

\subsection{Methods}

Procedure The procedures for this experiment were identical to that of Study 2.

Design The design was a 2 (bracket size: 1-year, 30-year) $\times 2$ (loss occurrence: no-loss, early-loss) between-subjects design. We also included three additional no-loss conditions: the 1-and-30 condition, the 100-year condition, and the 200-year condition. 
Participants in the 1-and-30 condition learned both the annual flood probability and the probability of at least one flood over 30 years. Those in the 100-year and 200-year conditions learned the probability of at least one flood over 100 years $(63 \%)$ or 200 years (87\%), respectively. Participants were randomly assigned to one of these seven conditions.

Measures We included the same measures as in Study 3.

Participants Participants were recruited from an online panel where they could be identified by zip code. We selected our sample from twelve US counties in which at least $50 \%$ of the flood insurance policies were owned by people in areas where flood insurance was not a requirement for getting a mortgage loan (i.e., outside the Special Flood Hazard Areas). This designation ensured that most of our participants were at risk of flood, were aware of the risk, and were likely to have experienced a flood and/or purchased flood insurance previously. The list of counties we sampled from can be found in Appendix B. A total of 1728 participants completed the study and passed at least one of the three comprehension check questions ( $69 \%$ female, $\mathrm{M}_{\mathrm{age}}=43.3$ years, $\left.\mathrm{SD}=15.9\right)$.

Payment Participants were offered a payment equivalent to those in the previous three studies and were told there was a chance they would earn a bonus based on their decisions. ${ }^{6}$ In addition, 14 participants were randomly selected (according to the Florida Pick-2 Lottery) to be paid based on their decisions; ten participants received $\$ 94.55$, and four received $\$ 95$.

\subsection{Results and discussion}

Our sampling procedure increased the proportion of people with flood experience and/ or purchasing flood insurance relative to our previous studies. Thirty seven percent indicated experiencing a flood disaster at least once compared to only $9 \%$ and $18.5 \%$ in Studies 2 and 3; 55\% indicated that they had purchased flood insurance while only $11.4 \%$ and $24.2 \%$ ever had this coverage in Studies 2 and 3 respectively. To determine whether these participants were more risk averse given their past flood-related experience than those in Study 2 (the experiment most similar to Study 4), we compared their self-reported risk tolerance $(0=$ not at all willing to take risks to $10=$ very willing to take risks). This measure has been found to be more predictive of behavior across domains than other risk measures (Charness et al. 2013; Dohmen et al. 2011). If anything, we find evidence of the opposite risk attitude: Participants in Study 4 reported being slightly more risk tolerant $(\mathrm{M}=4.58, \mathrm{SD}=2.47)$ than those in Study $2(N=2076$; $\mathrm{M}=4.12, \mathrm{SD}=2.53), \mathrm{t}(3093)=4.77, p<0.001$.

\footnotetext{
${ }^{6}$ Personal communication from the panel administrators regarding exact pay received by participants was as follows: "Our panelists select a number of different ways they would like to be incentivized. Some choose cash, travel miles, gift cards, points to gift card websites etc. Also, we often have to incentivize the last $10 \%$ of the respondents more in an effort to complete the survey. What we use as a good rule of thumb is that you can assume that $\sim 25-35 \%$ of the total cost per complete goes to the respondent." Since we were charged $\$ 7.50$ per participant, this means that participants received the equivalent of $\$ 1.88$ to $\$ 2.63$ in whatever medium they chose to receive their incentive.
} 
Broad bracket effect (H1) To test H1 and H2 (Table 1, column 5), we include only the four main conditions in which participants received information for either the narrow bracket (1-year probability) or the 30-year bracket $(N=1019)$. Fig. 1d displays the proportion of participants purchasing insurance in these four conditions. We find a significantly positive impact of the 30 -year broad bracket on choice in the direction predicted. Participants were 5.7 percentage points more likely to purchase insurance in the first round and prior to experiencing a loss than those who saw the 1-year probability, though this was a smaller increase than in Studies 2 and 3. One possible explanation for this difference is that people in this sample were already much more likely to purchase flood insurance in any given round. The baseline rate of insurance purchasing for people with the narrow bracket was $72 \%$, which is 10 percentage points higher than in the previous two studies. This lowered the proportion of decisions (i.e., choices to not purchase insurance) that could be influenced by broad bracketing. This effect holds when controlling for real-life flood experience as well as sex, age, education, income, and risk tolerance (Table A2, column 5).

Interaction with experience (H2) The broad bracket (“30-year prob.") did not interact with either the "round" or the "time since loss" variables (H2A supported), but it did interact with the "round after loss" variable: Participants in the 30-year conditions who experienced a flood loss in round 4 were 2 percentage points less likely (summing the coefficients on "30-year prob." and "30-year prob. x round after loss") to purchase flood insurance in the round right after the loss than participants who also experienced a loss in round 4 but who were in the 1-year condition. This effectively eliminated the broad bracket effect in round 5 for participants who witnessed the loss (H2B not supported). These effects hold when including control variables (Table A2, column 5).

Based on additional analyses (available upon request from the authors), we offer one possibility that could have led to the different result regarding $\mathrm{H} 2 \mathrm{~B}$ in this study than in our earlier studies. In Study 4, participants who experienced an early flood but were uninsured at the time behaved in a way that was opposite to participants who experienced an early flood but were insured. In Studies 1, 2 and 3, only the insured loss experiencers displayed an immediate reaction to loss (i.e., to drop insurance). In this case, the uninsured loss experiencers were much more likely to take up insurance in the subsequent round than were similar participants in Studies 1-3. In the previous studies, people who were uninsured did not differ in their behavior in round 5, whether or not they experienced a flood loss. This may be a function of the fact that Study 4 participants were likely to reside in high risk flood areas, so they were more likely to be affected by the occurrence of a flood than those in the earlier studies. The 1-year condition had a more even mix of insured and uninsured who experienced the loss shock, and because the main regression did not control for insured status, the counteracting effects of the insured and uninsured likely canceled each other out and led to a coefficient on "round after loss" that was not different from zero. The broad bracket conditions had higher proportions of insured participants overall than in the narrow bracket conditions, so the average effect detected is that of the insured participants - i.e., to drop one's insurance immediately after the flood shock. This observation demonstrates that broad bracketing could backfire in the case of a flood, at least in the immediate aftermath, if certain conditions hold-i.e., if broad bracketing has led to a significantly larger proportion of people being insured (than narrow bracketing), and 
if those insured people respond to a flood by dropping insurance (and the fewer uninsured people respond to a flood by purchasing a policy).

Simultaneous presentation of the narrow and broad brackets To test the impact of providing both the narrow and broad brackets, we conducted a regression that included only participants in three no-loss conditions: 1-year, 30-year, and 1-and-30 year $(N=$ 745; Table 2, column 1). For this analysis, the 1-and-30 condition served as the reference group. When controlling for round effects, we observed no statistically significant difference between the 1-and-30 condition and either of the other two conditions. The broad bracket was associated with a 5.5 percentage point higher take up of insurance in the first round relative to the 1-and-30 condition, but this was only marginally significant. Similar results hold when including control variables (Table A4, column 1). As there was no interaction between round and condition, we ran an exploratory regression where we provided more observations by not distinguishing between rounds so as to obtain more statistical power for differentiating between smaller effect sizes (Table 3, column 1). We found the 1-and-30 condition led to an average 2.2 percentage point decrease in insurance purchasing compared to the 30 -year condition - suggesting some choices are indeed skewed by the broad bracket — but was associated with a 3 percentage point increase in purchasing insurance relative to the 1 year condition - suggesting that not all choices are skewed but rather informed by the broad bracket. Supporting this latter point further, when controls for demographics, risk, and flood experience are included in the regression collapsed across rounds (Table A5, column 1), the 1-and-30 condition does not appear different from the broad bracket condition. However, this exploratory analysis collapsing across rounds was post-hoc, so we treat this as suggestive evidence that would need to be replicated in a future experiment. The proportion of people purchasing insurance in each of the 15 rounds for these three conditions is visualized in Fig. 2.

Table 2 Random-effects panel regressions including round variables for Study 4 comparing 1-year and 30year conditions to 1-and-30, 100-year, and 200-year conditions. Predicted variable is purchase of flood insurance

\begin{tabular}{llll}
\hline & $\begin{array}{l}\text { 1-and-30 as reference } \\
(1)\end{array}$ & $\begin{array}{l}100 \text {-year as reference } \\
(2)\end{array}$ & $\begin{array}{l}\text { 200-year as reference } \\
(3)\end{array}$ \\
\hline 1-year prob. & $-0.006(0.035)$ & $-0.005(0.035)$ & $-0.061^{+}(0.034)$ \\
30-year prob. & $0.055^{+}(0.033)$ & $0.057^{+}(0.033)$ & $0.001(0.032)$ \\
Round & $-0.002(0.002)$ & $-0.003(0.002)$ & $-0.004^{*}(0.002)$ \\
1-year prob. x round & $-0.003(0.003)$ & $-0.002(0.003)$ & $-0.001(0.003)$ \\
30-year prob. x round & $-0.004(0.003)$ & $-0.003(0.003)$ & $-0.002(0.003)$ \\
Constant & $0.701^{* * *}(0.024)$ & $0.699^{* * *}(0.025)$ & $0.755^{* * *}(0.023)$ \\
Participants & 745 & 742 & 734 \\
Observations & 11,175 & 11,130 & 11,010 \\
$\mathrm{R}^{2}$ & 0.005 & 0.005 & 0.006 \\
Adjusted $\mathrm{R}^{2}$ & 0.005 & 0.005 & 0.006 \\
\hline
\end{tabular}

Note: Heteroskedasticity-consistent $(\mathrm{HC} 1)$ standard errors in parentheses. Dependent variable is binary choice of certain loss over loss lottery. ${ }^{+} p<0.1 ;{ }^{*} p<0.05 ;{ }^{* *} p<0.01 ;{ }^{* * *} p<0.001$ 
Table 3 OLS regressions without round effects for Study 4 comparing 1-year and 30-year conditions to 1and-30, 100-year, and 200-year conditions. Predicted variable is purchase of flood insurance

\begin{tabular}{llll}
\hline & $\begin{array}{l}1 \text {-and-30 as reference } \\
(1)\end{array}$ & $\begin{array}{l}100 \text {-year as reference } \\
(2)\end{array}$ & $\begin{array}{l}\text { 200-year as reference } \\
(3)\end{array}$ \\
\hline 1-year prob. & $-0.030^{* *}(0.011)$ & $-0.023^{*}(0.011)$ & $-0.071^{* * *}(0.011)$ \\
30 -year prob. & $0.022^{*}(0.011)$ & $0.029^{* *}(0.011)$ & $-0.019^{+}(0.011)$ \\
Constant & $0.682^{* * *}(0.008)$ & $0.675^{* * *}(0.008)$ & $0.723^{* * *}(0.008)$ \\
Participants & 745 & 742 & 734 \\
Observations & 11,175 & 11,130 & 11,010 \\
$\mathrm{R}^{2}$ & 0.002 & 0.002 & 0.004 \\
Adjusted $\mathrm{R}^{2}$ & 0.002 & 0.002 & 0.004 \\
\hline
\end{tabular}

Note: Heteroskedasticity-consistent $(\mathrm{HC} 1)$ standard errors in parentheses. Dependent variable is binary choice of certain loss over loss lottery. ${ }^{+} \mathrm{p}<0.1 ;{ }^{*} \mathrm{p}<0.05 ;{ }^{* *} \mathrm{p}<0.01 ;{ }^{* * *} \mathrm{p}<0.001$

Irrelevantly large brackets To test whether participants ignored probability information calculated over irrelevantly large brackets, we conducted two regressions that included only participants in 1-year and 30-year no-loss conditions, as well as either those in the 100-year ( $N=742$; Table 2, column 2) or 200-year condition ( $N=734$; Table 2, column 3 ). For each of these regressions the 100-year and 200-year conditions, respectively, served as the reference condition. When including round effects, there were only marginally significant differences between the irrelevantly large brackets and the 1year and 30-year conditions. The same is true when including control variables (Table A4, columns 2 and 3). When excluding round variables (Table 3, columns 2 and 3), the differences become significant: Similar to the 1-and-30 condition, the 100year bracket has a dampened effect relative to the 30-year bracket (2.9 percentage points lower purchasing rate), but still yields greater purchasing rate than the 1-year bracket (2.3 percentage points). When controls for demographics, risk, and flood

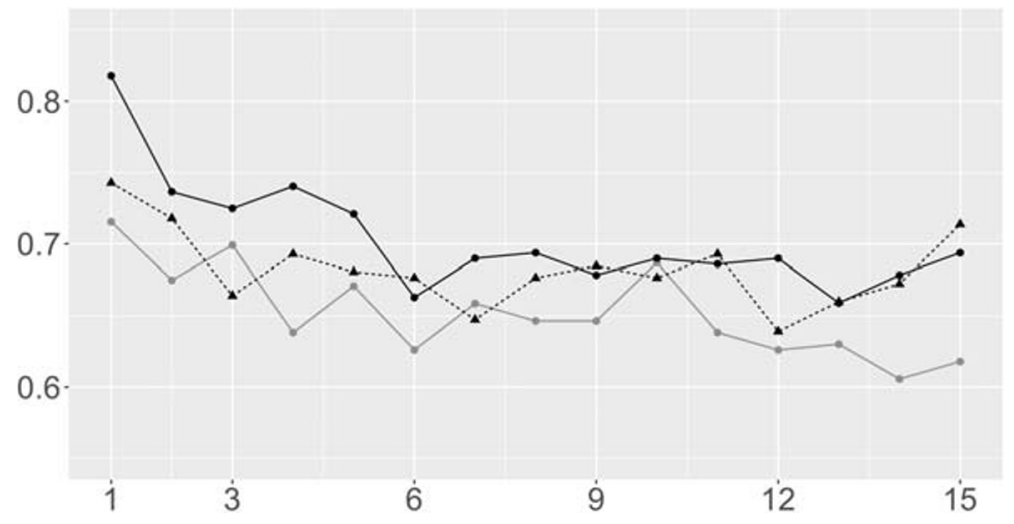

Fig. 2 Proportion of participants purchasing flood insurance in each round for Study 4. The x-axis indicates the round number. Only the three no-loss conditions are displayed: narrow-bracket no-loss (solid grey with circle markers ——- ), broad-bracket no-loss (solid black with circle markers - - -), 1-and-30 condition noloss (dashed black with triangle markers - - $\boldsymbol{\Delta}$ - -) 
experience are included in the regression collapsed across rounds (Table A5, column 2 ), the 100-year bracket appears no more effective than the 1-year bracket. The 200year condition has a similar effect as the 30 -year bracket, yielding an average purchase rate 7.1 percentage points higher than the 1-year bracket. When controls for demographics, risk, and flood experience are included in the regression collapsed across rounds (Table A5, column 3), the 200-year bracket still appears just as effective as the 30 -year bracket and more effective than the 1-year bracket in encouraging purchasing of insurance. These data suggest that people do not necessarily ignore "irrelevantly" large brackets. We further investigate how the size of the time horizon affects choices in Studies 5 and 6.

\section{Study 5: Changing the length of the time horizon}

In Study 5, we extend our investigation in two ways. First, we test whether the broad bracket effect generalizes to other time horizons, both shorter and longer than the 30-year frame. Second, we further investigate the mechanism and examine whether the broad bracket effect depends on the magnitude of the cumulative probability such that longer time horizons, which are associated with larger cumulative probabilities, lead more people to purchase insurance (H3). In Study 4 , we found the 200-year bracket was similarly effective to the 30 -year bracket, despite being associated with a much larger probability (i.e., 87\%). Here we wanted to see if we could replicate that finding and test several other brackets, including those associated with smaller probabilities than the 30-year time frame's $26 \%$ (i.e., $5 \%$ and $10 \%$ ).

\subsection{Methods}

Procedure The procedure for this experiment was the same as for Study 3, where rounds were non-independent, i.e., earnings carried across rounds.

Design Participants were randomly assigned to one of five, between-subjects conditions that only differed by length of the time horizon over which the cumulative probability information was presented: 1 year (1\%), 5 years $(5 \%)$, 10 years $(10 \%), 30$ years $(26 \%)$, or 200 years $(87 \%)$. No conditions included loss occurrences.

Measures We included the same measures and in the same format as in Study 3.

Participants A total of 1081 participants completed the survey and passed the comprehension check $\left(55 \%\right.$ female, $\mathrm{M}_{\mathrm{age}}=38.6$ years, $\left.\mathrm{SD}=12.2\right)$.

Payment Participants were paid on average \$1.96 (range: \$1-\$2). In addition, five participants were randomly chosen to receive payment based on their choices in the experiment; these participants received between $\$ 89.80$ to $\$ 93.30$. 


\subsection{Results and discussion}

Broad bracket effect (H1) Figure 3 displays the proportion of participants purchasing insurance in each of the five conditions. We included all five conditions for the main analysis, with the 1-year condition in round one as the reference group (Table 4, column 1). We find a significantly positive impact of all the broad-bracket conditions on flood insurance take up in the first round compared to the 1-year condition: The 5year bracket led to a 14.1 percentage point increase; the 10 -year led to a 16 percentage point increase; the 30 -year led to a 17.3 percentage point increase; and the 200 -year led to a 16.8 percentage point increase. The magnitude of these effects are a few percentage points smaller but still significant when controlling for real-life flood experience as well as sex, age, education, income, and risk tolerance (Table A6, column 1).

Interaction with experience $(\mathrm{H} 2)$ There was no average change in purchasing across rounds ("round"), nor was there any interaction of the round variable with any of the broad bracket conditions. These results hold with the inclusion of controls (Table A6, column 1).

Broad bracket size (H3) To examine whether the length of the time horizon among the broad bracket conditions was positively associated with purchasing insurance (H3), we ran two regressions that excluded the 1-year condition and used the 5-year condition as the reference group $(N=861$; Table 4 , columns 2 and 3$)$. In column 2, we ran a regression with indicator variables comparing the 10-year, 30-year, and 200-year conditions to the 5 -year reference condition. In column 3 , we defined a continuous variable that had four different values corresponding to the number of years associated with each of the different time horizon lengths (i.e., 5, 10, 30, and 200). We found no difference among the broad bracket conditions in either regression (or when including controls as in Table A6, columns 2 and 3), thus, rejecting H3. The longer time horizons displayed larger probabilities, so the fact that there was no difference across these

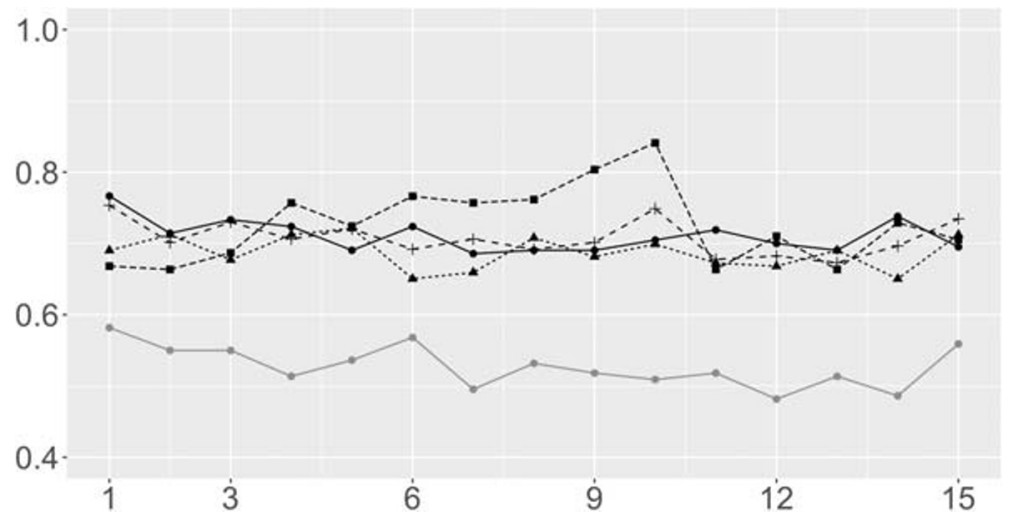

Fig. 3 Proportion of participants purchasing flood insurance in each round for Study 5. The x-axis indicates the round number. All five no-loss conditions are displayed: 1-year bracket (solid grey with circle markers ), 30-year bracket (solid black with circle markers - - - ) , 5-year bracket (dashed black with triangle markers - - $\boldsymbol{\Delta}$ - -), 10-year bracket (dashed black with square markers - - - - -), and 200-year bracket (dashed black with plus-sign markers --+- - ). All the broad bracket conditions are represented in black 
Table 4 Random-effects panel regressions for Study 5. Predicted variable is purchase of flood insurance
All time horizons
(1-year as reference)
Excluding 1-year condition
(5-year as reference)

(1)
Time horizons coded as indicator variables

(2)

Time horizon coded as continuous variable

(3)

\begin{tabular}{llll}
\hline 5-play prob. & $0.141^{* * * *}(0.041)$ & & \\
10-play prob. & $0.160^{* * *}(0.040)$ & $0.019(0.036)$ & \\
30-play prob. & $0.173^{* * * *}(0.040)$ & $0.032(0.037)$ & \\
200-play prob. & $0.168^{* * *}(0.041)$ & $0.027(0.038)$ & \\
Length of time horizon & & & $0.0001(0.0002)$ \\
Round & $-0.004(0.002)$ & $-0.001(0.002)$ & $-0.001(0.001)$ \\
5-play prob. x round & $0.002(0.003)$ & & \\
10-play prob. x round & $0.005^{+}(0.003)$ & $0.003(0.003)$ & \\
30-play prob. x round & $0.001(0.003)$ & $-0.001(0.003)$ & \\
200-play prob. x round & $0.002(0.003)$ & $-0.001(0.003)$ & $-0.00001(0.00001)$ \\
Length of time horizon x round & & & $0.712^{* * *}(0.016)$ \\
Constant & $0.556^{* * *}(0.031)$ & $0.697^{* * *}(0.027)$ & 861 \\
Participants & 1081 & 861 & 12,915 \\
Observations & 16,215 & 12,915 & 0.0003 \\
$\mathrm{R}^{2}$ & 0.004 & 0.001 & 0.00004 \\
Adjusted R & 0.003 & 0.0001 & \\
\hline
\end{tabular}

Note: Earnings carried over across rounds in Study 5 (non-independent rounds). For column one, the reference group is the 1-year condition in round one. For columns two and three, the reference group is the 5-year condition in round one. In column three, the "length of time horizon" variable is a continuous variable with values equal to the length of the time horizon corresponding to the condition $\{1,5,10,30,200\}$. Heteroskedasticity-consistent ( $\mathrm{HC} 1)$ standard errors in parentheses. Dependent variable is binary choice to purchase insurance. ${ }^{+} p<0.1{ }^{* * *} \mathrm{p}<0.001$

different horizions (5-year, 10-year, 30-year, or 200-year) suggests that the size of the probability is, therefore, not the only driving force behind the broad bracket effect. One potential explanation for this pattern is that probability size is positively related to protective behavior, but there is also a counteracting time horizon effect, as proposed by $\mathrm{H} 4$. We examine this in the next experiment.

\section{Study 6: Probability size versus time horizon length}

Study 6 examines the roles played by probability size and time horizon length in creating the broad bracket effect. H4 proposes that decision makers are sensitive to both probability size and time horizon length but in the opposite direction: The greater the cumulative probability, the more people will take protective action, but the longer the time horizon, the less people will take protective action. 


\subsection{Methods}

Procedure The procedure for this experiment was the same as for Study 5, except that participants made only one decision (i.e., one round). However, participants were told that they would not be told the number of rounds they would face ahead of time, and that they could potentially play up to 25 rounds. The talers conversion was changed to 10,000 talers per $\$ 1$ so that the maximum possible earnings from one's decisions in the experiment was $\$ 9.50$.

Design The study used a 2(time horizon length: 10 years, 200 years) $\times 5$ (cumulative probability size: $1 \%, 10 \%, 26 \%, 63 \%, 87 \%$ ) between-subjects design, and participants were randomly assigned to one of these ten conditions. We chose a set of cumulative probabilities that spanned the range of values between 0 and $100 \%$ and were used in our previous studies. The same set of probabilities were used for each time horizon condition. Note that these probability-time horizon combinations all reflect risks with different underlying annual probabilities.

Measures In addition to the measures used in the earlier studies, we asked each participant to guess the one-year probability for their event ("What do you think (make your best guess) is the probability (in percent) of at least one flood over the next 1 year?" [free response number between 0 to 100 with up to two decimal places]. We also included a short, 3-item subjective numeracy scale (McNaughton et al. 2015).

Participants A total of 2303 participants completed the survey and passed the comprehension check $\left(57 \%\right.$ female, $\mathrm{M}_{\mathrm{age}}=37.3$ years, $\left.\mathrm{SD}=11.6\right)$.

Payment Participants were paid on average $\$ 0.70$ (range: $\$ 0.50-\$ 0.75$ ). In addition, 21 participants were randomly chosen to receive payment based on their choices in the experiment; 16 participants received $\$ 9.40$, while five received $\$ 9.50$.

\subsection{Results and discussion}

Table 5 displays the main results of Study 6, where the predicted variable is the percentage of people purchasing insurance. Fig. 4 displays the predicted values (lines) and observed values (points) for the proportion of participants purchasing insurance in each condition. The cumulative probability associated with each condition is indicated on the $\mathrm{x}$-axis and the length of the time horizon is represented by the line type and point shape. The $95 \%$ confidence bands for the predicted values are shown.

Probability size versus time horizon length $(\mathrm{H} 4)$ To examine the relative contribution of probability size and time horizon length on behavior, we ran an OLS regression (one observation per participant) with purchase decision as the predicted variable, categorical variables for probability size ( $1 \%$ probability as the reference category), time horizon length (10 years as the reference), and the interaction of time horizon with the probability indicators as the predictor variables (Table 5). As expected, we found a positive association between cumulative probability size and purchasing: Relative to 
Table 5 OLS regressions for Study 6. Predicted variable is purchase of flood insurance

\begin{tabular}{lll}
\hline & Main effects only & Interaction \\
\hline & $(1)$ & $(2)$ \\
Prob. $=0.10$ & $0.192^{* * * *}(0.032)$ & $0.196^{* * * *}(0.046)$ \\
Prob. $=0.26$ & $0.235^{* * * *}(0.032)$ & $0.238^{* * *}(0.045)$ \\
Prob. $=0.63$ & $0.320^{* * * *}(0.031)$ & $0.423^{* * * *}(0.041)$ \\
Prob. $=0.87$ & $0.382^{* * * *}(0.030)$ & $0.425^{* * *}(0.041)$ \\
200-year time horizon & $-0.096^{* * *}(0.020)$ & $-0.033(0.045)$ \\
Prob. $=0.10 \times 200$-year horizon & & $-0.007(0.065)$ \\
Prob. $=0.26 \times 200$-year horizon & & $-0.007(0.064)$ \\
Prob. $=0.63 \times 200$-year horizon & & $-0.215^{* * *}(0.062)$ \\
Prob. $=0.87 \times 200$-year horizon & & $-0.087(0.060)$ \\
Constant & $0.411^{* * *}(0.025)$ & $0.380^{* * * *}(0.032)$ \\
Observations & 2303 & 2303 \\
$\mathrm{R}^{2}$ & 0.080 & 0.087 \\
Adjusted $\mathrm{R}^{2}$ & 0.078 & 0.083 \\
\hline
\end{tabular}

Note: Heteroskedasticity-consistent $(\mathrm{HC} 1)$ standard errors in parentheses. Dependent variable is binary choice to purchase insurance. ${ }^{+} p<0.1 ;{ }^{*} p<0.05 ;{ }^{* *} p<0.01 ;{ }^{* * *} p<0.001$

seeing the $1 \%$ probability, participants who saw higher probabilities were more likely to take up insurance. This effect increases as the probability increases across the four probability levels $(10 \%, 26 \%, 63 \%$, and $87 \%)$, whether or not the interaction term was included in the regression. We also found that, when an interaction term was included, there was no main effect of increasing the time horizon to 200 years, but there was an interaction: The longer time horizon did not have as much impact for smaller cumulative loss probabilities as it did for larger cumulative loss probabilities. To illustrate this point, when the time horizon was 200 years, participants seeing the $63 \%$

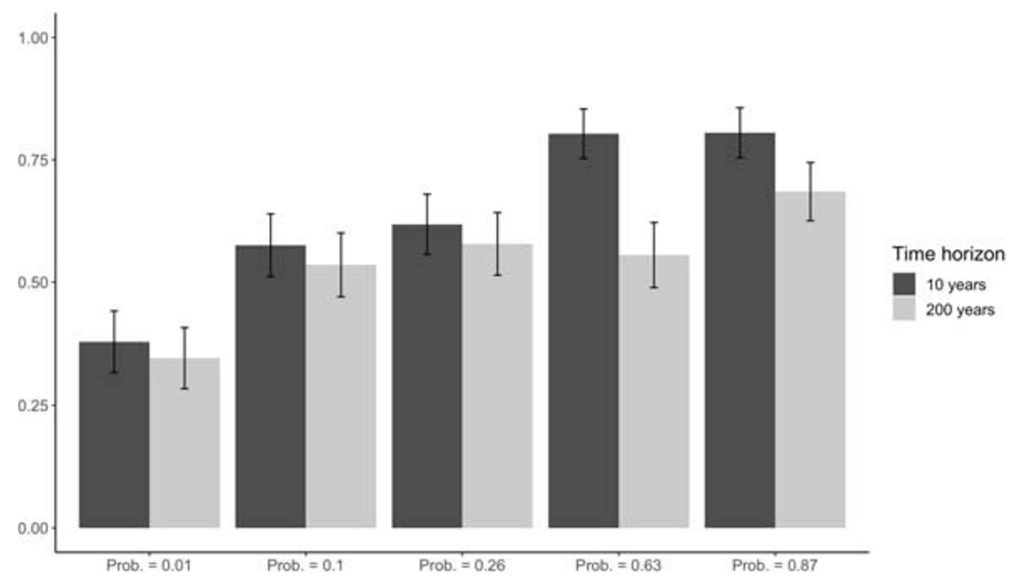

Fig. 4 Probability of purchasing flood insurance in each condition for Study 6. The x-axis indicates the cumulative probability displayed to participants in a given condition. The error bars represent $95 \%$ confidence intervals 
probability were 21 percentage points more likely to purchase insurance compared to those seeing the $1 \%$ probability, an effect which is half the size of that for the 10 -year time horizon. However, this interaction effect was only statistically significant when the cumulative probability was stated as $63 \%$. These results hold with control variables for real-life flood experience as well as sex, age, education, income, risk tolerance, and numeracy (Table A7).

\section{General discussion}

We investigated whether the effect of broad bracketing is present when using a simpler, more scalable presentation format (presenting cumulative loss probabilities), and whether the effect persists over time when choices have to be made repeatedly and in the face of feedback. Furthermore, we examined the mechanism behind broad bracketing by isolating the relative importance of probability size and bracket size. Examining these questions not only advances theory but also helps assess whether broad bracketing can be used as a risk communication tool to motivate people to protect themselves from catastrophic losses. For this investigation, we focused on the example of flooding.

The findings from our six studies have established that broad bracketing can be robust to repetition and feedback, both of which are key features of the decision environment that people face when making protective decisions. Specifically, we find that providing the cumulative probability of experiencing at least one negative event over multiple periods compared to the probability of experiencing the event during one period leads more people to take protective action against a risk. Study 1 demonstrates that this effect occurs in an abstract setting and Studies 2-5 show that it also occurs in the richer, more ecologically relevant situation of insuring one's house and assets against a catastrophic flood, even after controlling for real-life personal experience with floods.

Importantly, we find that, for the most part, this effect lasts across 15 rounds of decisions with feedback after each decision, whether or not one experiences a loss. In one case-Study 4 with the flood-prone sample-we found that the broad bracket effect disappeared only in the immediate aftermath of experiencing a loss. Those in the broad bracket condition then displayed similar purchase rates to those in the narrow bracket condition. As discussed in the discussion section of Study 4, one key factor determining whether the broad bracket effect is robust to experiencing a loss is the proportion of people who are insured versus uninsured at the time of a loss. Both types seemed to respond to the experience of a loss - the former would drop insurance, while the latter would take up insurance. The "dropping" effect was larger than the "taking up" effect in the broad bracket than the narrow bracket group because more people purchased insurance when presented with $26 \%$ chance of at least one flood in 30 years than a $1 \%$ chance of a flood next year. Even if a loss can undermine the broad bracket in its immediate aftermath, examination of the data in Fig. 1d reveals that the broad bracket effect returns after round 11. Thus, even if the broad bracket effect is not impenetrable to experience, it at least seems resilient. 
We find that the broad bracket effect is also robust to other features of the decision environment. In Study 3, we find that allowing earnings and losses to carry forward across rounds (as they do in real life) does not change the main broad bracketing result. In the same study, we find that, although increasing the cost of the protective action (i.e., the price of flood insurance) lowers the proportion of people taking the protective action across all conditions, as one would expect, the higher cost does not decrease the size of the broad bracket effect. In Study 4, we find that the broad bracket increases protective behavior even among people who live in a floodplain and have experienced the flood risk in real life. We also discover that presenting the narrow and broad brackets simultaneously reduces the broad bracket effect, but does not eliminate it.

Our investigation also provides insights into the mechanism behind broad bracketing. The combined findings from Studies 5 and 6 demonstrate that the broad bracket effect is not solely driven by the size of the probabilities: while a larger cumulative probability leads more people to take protective action, this effect is somewhat dampened for longer time horizons, particularly for larger probabilities. These results indicate that both these elements associated with broad bracketing inform decision makers' judgments.

\subsection{Theoretical implications}

Our findings have a number of important theoretical implications. First, we find that a more scalable, simple form of broad bracketing that displays only the probability of loss (i.e., extending the time horizon) can have the same effect in increasing risk averse behavior as previously demonstrated in the loss domain for the standard form of broad bracketing (i.e., presenting a full distribution of outcomes; Webb and Shu 2017). Second, we find that the broad bracket effect is robust to repetition and feedback, which has not been previously demonstrated. In particular, the effect is not only not eliminated in the face of experience, but it largely remains the same size over time.

Third, this latter finding contributes to the literature on decisions from description (e.g. characterizing probabilities of a loss) versus decisions from experience (e.g feedback on a flood loss). Past research found that decisions made in the presence of both description and experience converged with the pattern of decisions made solely from experience, implying that people eventually ignore description and focus solely on experience (Jessup et al. 2008; Lejarraga and Gonzalez 2011; Newell et al. 2016; Rakow et al. 2008; Yechiam and Busemeyer 2006). This provides reasonable justification to believe the broad bracket effect will disappear over time, or at least decrease in size. However, across all our studies, we found this not to be the case: Even when participants have the exact same sequence of experiences, their choices are significantly influenced by the description they receive, that is, participants with a broadly bracketed probability description make different choices than those with the narrowly bracketed probability description. Furthermore, we observed almost no change in the size of this effect with the exception of one (Study 4) of our five studies examining this question. Future research is needed to rectify these diverging observations.

Fourth, our findings advance our understanding of the mechanism underlying broad bracketing. We show that broad bracketing is not solely the result of error-prone inference of the one-period probability, or the skewing of risk preferences. Even when given both one-period and cumulative probabilities, we found directional evidence that 
participants are still influenced in their choices by the presence of the cumulative probability (though to a lesser extent), suggesting they derive additional value from that information. Furthermore, the size of the cumulative probability of the loss is an important driver of the effect, but it is not the only driver. Participants discount a given cumulative probability more when it is presented using a longer time horizon, reflecting an understanding that it represents an event with a lower underlying probability of occurring.

\subsection{Policy implications}

Presenting the cumulative loss probability can be used by risk communicators as a powerful way to motivate protective behavior against rare catastrophic events. However, the broad bracket will likely only change behavior around rare events if it involves a cumulative probability that is large enough that people will not ignore it. For instance, extending the time horizon over 10 years might be effective for an event with a $1 \%$ annual probability (which translates to about a $10 \%$ probability of one or more floods over 10 years), but might not be effective for an event with a $0.1 \%$ annual probability (which translates to a $1 \%$ probability of one or more floods over 10 years). Indeed, Study 6 demonstrates that the " $10 \%$ over 10 years" leads to more than a $55 \%$ take-up of flood insurance, but the " $1 \%$ over 10 years" leads to less than $40 \%$ take-up of flood insurance-more than a 15 percentage point difference. This finding suggests that when an event is really rare, it may be worthwhile for risk communicators to use longer time horizons. A $0.1 \%$ annual chance might be presented as an $18 \%$ chance of one or more floods over 200 years. If communicators are worried that doing so may bias decision makers too far away from their natural preferences, results from Study 4 show that communicators can simultaneously present both the cumulative and one-period probabilities without entirely eliminating a potential broad bracketing effect.

Based on our findings, for events with an annual risk of $1 \%$ or more, there is little need to use time horizons longer than five or ten years. Study 5 revealed that extending the time horizon to five years substantially increased protective behavior compared to presenting the one-year probability of loss; however, extending the time horizon even further (10 years, 30 years, 200 years) did not result in any additional increase in protective behavior. People also seem to prefer shorter time periods. Exploratory questions in Studies 3-5 indicated that the majority of people preferred a time horizon of 10 years or less in specifying the likelihood of a flood when making decisions on purchasing insurance. The ideal time horizon will likely vary for events of different underlying probabilities of occurring.

\subsection{Future research directions}

Future research is needed to deepen our understanding of the dynamics of broad bracketing and its application to risk communication. It is currently unclear whether different types of broad bracketing presentations will have different impacts on behavior. We tested an alternative type of broad bracketing (cumulative loss probabilities) in which we presented only the cumulative probability of one or more losses and the timeframe over which that probability was calculated. This differs from the standard broad bracketing presentation of the full distribution of outcomes. Though we found 
similar impacts to previous work, it is unclear whether there could be unique benefits or risks to each format.

Utilizing the cumulative loss probability format, we were able to demonstrate for the first time that the length of the time horizon impacts the effectiveness of a broad bracketing framing. Though we did not focus on this in our investigation, in Study 6 we found the dampening of the longer time horizon to be concentrated among cumulative probabilities greater than $50 \%$. Cumulative probabilities lower than $50 \%$ yielded similar behavior regardless of whether they were calculated over 10 or 200 years. Furthermore, though we found a positive relationship between cumulative probability size and the likelihood of taking protective action even for the longer time horizon of 200 years, it is unclear whether there is a possibility that a time horizon can be so long that it backfires. Study of this potentially non-linear relationship between attention to the broad bracket and the length of the time horizon could provide further insights into how people respond to the risk of rare events.

Further work is also needed to examine whether the length of the time horizon interacts with the number of decisions a person expects to make. For instance, in Study 5 , we noticed a substantial dip in protective action for participants in the 5-year and 10year conditions in the round immediately following these specific rounds. Some participants who received the 5-year probability of at least one flood (5\%) and did not experience a loss during the first five rounds, seemed to believe they were "in the clear." Thus, whether a risk communicator provides a broad bracket that is larger or smaller than the number of decisions a decision maker will be making may influence whether such dips in protective behavior are observed.

The extent to which the broad-bracketing effect is observed in field studies of actual decisions where there are real economic consequences and other demands on people's attention is another important area for future research. There are reasons to believe the effect of a broad bracket in the real world might be smaller (e.g., due to switching costs) and reasons to believe it might be larger (e.g., greater emotional salience of protecting one's home and finances). In line with this, a past meta-analysis comparing lab and field results found that, while the correspondence between lab and field effect sizes was actually quite high $(\mathrm{r}=0.73)$, some effects are overestimated in the lab while others are underestimated (Anderson et al. 1999). In our experiments, we observed populationbased differences: The broad bracketing effect for people living in a floodplain was smaller than for participants who did not live in a floodplain and the base rate of purchasing insurance was much higher within this floodplain sample than in the other studies. One reason for this difference might be that most of these individuals were convinced that they should purchase insurance whether the probability of a future flood was presented for next year or over a 30-year period.

Future work could benefit by examining variation across individuals with respect to whether and to what extent broad bracketing impacts behavior. In particular, individual differences in numeracy and intuitive math operations may influence the broad bracket effect. In Study 4, we observed that providing both the 1-year and 30-year probabilities resulted in a decrease in the size of the broad bracketing effect, suggesting that this experimental condition was helping some people correct error-prone inferences they would have made if they were only given the broad bracket. Thus, the size of the broad bracket impact on a population may depend on the proportion of people who make such inferences in the absence of full information. In Study 6, we measured numeracy 
explicitly, and while this variable did seem to be negatively associated with the broad bracket effect when not controlling for any other individual differences, once we controlled for demographics (including education), risk tolerance, and flood experience, the relationship was no longer significant. However, it is still unclear how and why these individual differences may play a role in the broad bracket effect.

Finally one needs controlled experiments and field studies where the probabilities of a loss are likely to change over time, as is the case with respect to climate change and its impact on the chances of flood-related damage in future years. If people are told or believe that future probabilities are uncertain and dynamic they may place less weight on the likelihood of a event occurring whether the information is presented as a narrow bracket or as a broad bracket over different time horizons.

Supplementary Information The online version contains supplementary material available at https:/doi.org/ 10.1007/s11166-020-09343-4.

Acknowledgements We wish to express gratitude to Allyson Root, Rick Larrick, Ray Sin, and George Wu for feedback on the experimental design and/or earlier drafts of this paper. We appreciate helpful discussions with our colleagues at the Wharton Risk Center throughout the development of this paper: Jeff Czajkowski, Carol Heller, Carolyn Kousky, Brett Lingle, Robert Meyer, Marilyn Montgomery, and Gina Tonn. We would also like to thank Nyzinga Patterson for administrative support in running the experiments. We appreciate additional feedback from participants at the 2018 SABE sessions at the WEAI conference and the 2018 meeting of the Society for Judgment and Decision Making.

Availability of data and material All data, power analyses, and pre-registrations are available on the Open Science Framework (OSF) at: https://osf.io/mejf5/?view_only=9b8760dca9714e85bc178f290140125e.

Authors' contributions All authors contributed in a significant way to the manuscript.

Funding Support for this research comes from a grant from the Sloan Foundation (G-2018-11100 / SUB1804); a National Science Foundation (NSF) grant (EAR-1520683 / SUB0000091) through Princeton University; the Geneva Association; the Travelers Risk Management and Leadership project; and the Wharton Risk Management and Decision Processes Center's Extreme Events project.

\section{Compliance with ethical standards}

Conflict of interest None of the authors has any conflicts of interest.

Code availability Data was analyzed using R and STATA. Code for data analysis available upon request.

Open Access This article is licensed under a Creative Commons Attribution 4.0 International License, which permits use, sharing, adaptation, distribution and reproduction in any medium or format, as long as you give appropriate credit to the original author(s) and the source, provide a link to the Creative Commons licence, and indicate if changes were made. The images or other third party material in this article are included in the article's Creative Commons licence, unless indicated otherwise in a credit line to the material. If material is not included in the article's Creative Commons licence and your intended use is not permitted by statutory regulation or exceeds the permitted use, you will need to obtain permission directly from the copyright holder. To view a copy of this licence, visit http://creativecommons.org/licenses/by/4.0/. 


\section{References}

Anderson, C. A., Lindsay, J. J., \& Bushman, B. J. (1999). Research in the psychological laboratory. Current Directions in Psychological Science, 8(1), 3-9. https://doi.org/10.1111/1467-8721.00002.

Ayton, P., \& Fischer, I. (2004). The hot hand fallacy and the gambler's fallacy: Two faces of subjective randomness? Memory \& Cognition, 32(8), 1369-1378. https://doi.org/10.3758/BF03206327.

Barron, G., \& Erev, I. (2003). Small feedback-based decisions and their limited correspondence to descriptionbased decisions. Journal of Behavioral Decision Making, 16(3), 215-233. https://doi.org/10.1002/bdm. 443.

Barron, G., \& Yechiam, E. (2009). The coexistence of overestimation and underweighting of rare events and the contingent recency effect. Judgment and Decision making, 4(6), 447-460. http://www.doaj.org/doaj? func $=$ openurl \&genre $=$ article $\&$ issn $=19302975 \&$ date $=2009 \&$ volume $=4 \&$ issue $=6 \&$ spage $=447$.

Benartzi, S., \& Thaler, R. H. (1999). Risk aversion or myopia? Choices in repeated gambles and retirement investments. Management Science, 45(3), 364-381. https://doi.org/10.1287/mnsc.45.3.364.

Charness, G., Gneezy, U., \& Imas, A. (2013). Experimental methods: Eliciting risk preferences. Journal of Economic Behavior \& Organization 87, 43-51.

Charness, G., Gneezy, U., \& Halladay, B. (2016). Experimental methods: Pay one or pay all. Journal of Economic Behavior \& Organization, 131, 141-150. https://doi.org/10.1016/j.jebo.2016.08.010.

Clot, S., Grolleau, G., \& Ibanez, L. (2018). Shall we pay all? An experimental test of random incentivized systems. Journal of Behavioral and Experimental Economics, 73(February), 93-98. https://doi.org/10. 1016/j.socec.2018.01.004.

Croson, R., \& Sundali, J. (2005). The gambler's fallacy and the hot hand: Empirical data from casinos. Journal of Risk and Uncertainty, 30(3), 195-209.

De La Maza, C., Davis, A., Gonzalez, C., \& Azevedo, I. (2019). Understanding cumulative risk perception from judgments and choices: An application to flood risks. Risk Analysis, 39(2), 488-504. https://doi.org/ 10.1111/risa.13206.

Dohmen, T., Falk, A., Huffman, D., Sunde, U., Schupp, J., \& Wagner, G. G. (2011). Individual risk attitudes: Measurement, determinants, and behavioral consequences. Journal of the European Economic Association, 9(3), 522-550. https://doi.org/10.1111/j.1542-4774.2011.01015.x.

Doyle, J. K. (1997). Judging cumulative risk. Journal of Applied Social Psychology, 27(6), 500-524. https:// doi.org/10.1111/j.1559-1816.1997.tb00644.x.

Dumm, R. E., Eckles, D. L., Nyce, C., \& Volkman-Wise, J. (2020). The representative heuristic and catastrophe-related risk behaviors. Journal of Risk and Uncertainty, 60(2), 157-185. https://doi.org/10. 1007/s11166-020-09324-7.

FEMA. (2018). Fact sheet: FEMA assistance is a supplement to private recovery efforts - not a substitute. Retrieved from https://www.fema.gov/news-release/2018/06/14/fact-sheet-fema-assistance-supplementprivate-recovery-efforts-not-substitute.

Fuller, R., Dudley, N., \& Blacktop, J. (2004). Older people's understanding of cumulative risks when provided with annual stroke risk information. Postgraduate Medical Journal, 80(949), 677-678. https://doi.org/10. 1136/pgmj.2004.019489.

Gneezy, U., \& Potters, J. (1997). An experiment on risk taking and evaluation periods. The Quarterly Journal of Economics, 112(2), 631-645. Retrieved from http://qje.oxfordjournals.org/content/112/2/631.short.

Hardin, A. M., \& Looney, C. A. (2012). Myopic loss aversion: Demystifying the key factors influencing decision problem framing. Organizational Behavior and Human Decision Processes, 117(2), 311-331. https://doi.org/10.1016/j.obhdp.2011.11.005.

Hershey, J. C., \& Schoemaker, P. J. H. (1980). Risk taking and problem context in the domain of losses: An expected utility analysis. Journal of Risk and Insurance, 47(1), 111-132.

Hertwig, R., Barron, G., Weber, E. U., \& Erev, I. (2004). Decisions from experience and the effect of rare events in risky choice. Psychological Science, 15(8), 534-539. https://doi.org/10.1111/j.0956-7976.2004. 00715.x.

Hogarth, R. M., \& Einhorn, H. J. (1992). Order effects in belief updating: The belief-adjustment model. Cognitive Psychology, 24(1), 1-55. https://doi.org/10.1016/0010-0285(92)90002-J.

Jarvik, M. E. (1951). Probability learning and a negative recency effect in the serial anticipation of alternative symbols. Journal of Experimental Psychology, 41(4), 291-297. https://doi.org/10.1037/h0056878.

Jaspersen, J. G. (2016). Hypothetical surveys and experimental studies of insurance demand: A review. Journal of Risk and Insurance, 83(1), 217-255. https://doi.org/10.1111/jori.12100. 
Jessup, R. K., Bishara, A. J., \& Busemeyer, J. R. (2008). Feedback produces divergence from prospect theory in descriptive choice. Psychological Science, 19(10), 1015-1022. https://doi.org/10.1111/j.1467-9280. 2008.02193.x.

Kahneman, D., \& Lovallo, D. (1993). Timid choices and bold forecasts: A cognitive perspective on risk taking. Management Science, 39(1), 17-31. https://doi.org/10.1287/mnsc.39.1.17.

Kahneman, D., \& Tversky, A. (1972). Subjective probability: A judgment of representativeness. Cognitive Psychology, 3(3), 430-454. https://doi.org/10.1016/0010-0285(72)90016-3.

Kahneman, D., \& Tversky, A. (1979). Prospect theory: An analysis of decision under risk. Econometrica, 47(2), 263-292.

Keller, C., Siegrist, M., \& Gutscher, H. (2006). The role of the affect and availability heuristics in risk communication. Risk Analysis, 26(3), 631-639. https://doi.org/10.1111/j.1539-6924.2006.00773.x.

Knäuper, B., Kornik, R., Atkinson, K., Guberman, C., \& Aydin, C. (2005). Motivation influences the underestimation of cumulative risk. Personality and Social Psychology Bulletin, 31(11), 1511-1523. https://doi.org/10.1177/0146167205276864.

Kunreuther, H. (1996). Mitigating disaster losses through insurance. Journal of Risk and Uncertainty, 12(2-3), 171-187. https://doi.org/10.1007/BF00055792.

Kunreuther, H., \& Michel-Kerjan, E. (2015). Demand for fixed-price multi-year contracts: Experimental evidence from insurance decisions. Journal of Risk and Uncertainty, 51(2), 171-194. https://doi.org/10. 1007/s11166-015-9225-4.

Kunreuther, H., Ginsberg, R., Miller, L., Sagi, P., Slovic, P., Borkan, B., \& Katz, N. (1978). Disaster insurance protection: Public policy lessons. John Wiley \& Sons, Inc.

Lejarraga, T., \& Gonzalez, C. (2011). Effects of feedback and complexity on repeated decisions from description. Organizational Behavior and Human Decision Processes, 116(2), 286-295. https://doi.org/ 10.1016/j.obhdp.2011.05.001.

Linville, P. W., Fischer, G. W., \& Fischhoff, B. (2015). AIDS risk perceptions and decision biases. In J. B. Pryor \& G. D. Reeder (Eds.), The social psychology of HIV infection (Vol. 24, pp. 1-38). Hillsdale NJ: Lawrence Erlbaum. https://doi.org/10.4324/9781315722924.

Long, H. (2017). Where Harvey is hitting hardest, 80 percent lack flood insurance. Washington, DC: The Washington Post. Retrieved from https:/www.washingtonpost.com/news/wonk/wp/2017/08/29/whereharvey-is-hitting-hardest-four-out-of-five-homeowners-lack-flood-insurance/?utm_term=.62cee8661b99.

Looney, C. A., \& Hardin, A. M. (2009). Decision support for retirement portfolio management: Overcoming myopic loss aversion via technology design. Management Science, 55(10), 1688-1703. https://doi.org/10. 1287/mnsc.1090.1052.

Lypny, G. J. (1993). An experimental study of managerial pay and firm hedging decisions. Journal of Risk and Insurance, 60(2), 208-229.

MacKinnon, J. G., \& White, H. (1985). Some heteroskedasticity consistent covariance matrix estimators with improved finite sample properties. Journal of Econometrics, 29(3), 305-325. https://doi.org/10.1016/ 0304-4076(85)90158-7.

McClelland, G. H., Schulze, W. D., \& Coursey, D. L. (1993). Insurance for low-probability hazards: A bimodal response to unlikely events. Journal of Risk and Uncertainty, 7(1), 95-116. https://doi.org/10. 1007/BF01065317.

McNaughton, C. D., Cavanaugh, K. L., Kripalani, S., Rothman, R. L., \& Wallston, K. A. (2015). Validation of a short, 3-item version of the subjective numeracy scale. Medical Decision Making, 35(8), 932-936. https://doi.org/10.1177/0272989X15581800.

Meyer, R., \& Kunreuther, H. (2017). The ostrich paradox: Why we underprepare for disasters. Wharton School Press.

Newell, B. R., Rakow, T., Yechiam, E., \& Sambur, M. (2016). Rare disaster information can increase risktaking. Nature Climate Change, 6(2), 158-161. https://doi.org/10.1038/nclimate2822.

Plonsky, O., Teodorescu, K., \& Erev, I. (2015). Reliance on small samples, the wavy recency effect, and similarity-based learning. Psychological Review, 122(4), 621-647. https://doi.org/10.1037/a0039413.

Rakow, T., Demes, K. A., \& Newell, B. R. (2008). Biased samples not mode of presentation: Re-examining the apparent underweighting of rare events in experience-based choice. Organizational Behavior and Human Decision Processes, 106(2), 168-179. https://doi.org/10.1016/j.obhdp.2008.02.001.

Read, D., Loewenstein, G. F., \& Rabin, M. (1999). Choice bracketing. Journal of Risk and Uncertainty, 19(3), 171-197. https://doi.org/10.1023/A:1007879411489.

Redelmeier, D. A., \& Tversky, A. (1992). On the framing of multiple prospects. Psychological Science, 3(3), 191-193. https://doi.org/10.1111/j.1467-9280.1992.tb00025.x. 
Robinson, P. J., \& Botzen, W. J. (2018). The impact of regret and worry on the threshold level of concern for flood insurance demand: Evidence from Dutch homeowners. Judgment and Decision making, 13(2), 237-245. Retrieved from http://www.sjdm.org/journal/18/18201a/jdm18201a.html.

Samuelson, P. A. (1963). Risk and uncertainty: A fallacy of large numbers. Scientia, 98, 108-113. Retrieved from http://www.casact.org/pubs/forum/94sforum/94sf049.pdf.

Shaklee, H., \& Fischhoff, B. (1990). The psychology of contraceptive surprises: Cumulative risk and contraceptive effectiveness. Journal of Applied Social Psychology, 20(5), 385-403. https://doi.org/10. 1111/j.1559-1816.1990.tb00418.x.

Slovic, P., Fischhoff, B., Lichtenstein, S., Corrigan, B., Slovic, P., Fischhoff, B., \& Lichtenstein, S. (1977). Preference for insuring against probable small losses: Insurance implications. The Journal of Risk and Insurance, 44(2), 237-258.

Slovic, P., Fischhoff, B., \& Lichtenstein, S. (1978). Accident probabilities and seat belt usage: A psychological perspective. Accident Analysis and Prevention, 10(4), 281-285. https://doi.org/10.1016/00014575(78)90030-1.

Thaler, R. H., Tversky, A., Kahneman, D., \& Schwartz, A. (1997). The effect of myopia and loss aversion on risk taking: An experimental test. The Quarterly Journal of Economics, 112(2), 647-661. https://doi.org/ 10.1162/003355397555226.

Tversky, A., \& Kahneman, D. (1973). Availability: A heuristic for judging frequency and probability. Cognitive Psychology, 5(2), 207-232. https://doi.org/10.1016/0010-0285(73)90033-9.

Visschers, V. H. M., Meertens, R. M., Passchier, W. W. F., \& de Vries, N. N. K. (2009). Probability information in risk communication: A review of the research literature. Risk Analysis, 29(2), 267-287. https://doi.org/10.1111/j.1539-6924.2008.01137.x.

Webb, E. C., \& Shu, S. B. (2017). Is broad bracketing always better? How broad decision framing leads to more optimal preferences over repeated gambles. Judgment and Decision making, 12(4), 382-395.

Weber, E. U., Shafir, S., \& Blais, A.-R. (2004). Predicting risk sensitivity in humans and lower animals: Risk as variance or coefficient of variation. Psychological Review, 111(2), 430-445. https://doi.org/10.1037/ 0033-295X.111.2.430.

Yechiam, E., \& Busemeyer, J. R. (2006). The effect of foregone payoffs on underweighting small probability events. Journal of Behavioral Decision Making, 19(1), 1-16. https://doi.org/10.1002/bdm.509.

Yin, H., Chen, J., Kunreuther, H., \& Michel-Kerjan, E. (2016). Availability heuristic and gambler's fallacy over time in a natural disaster insurance choice setting. SSRN Working Paper. https://doi.org/10.2139/ ssrn. 2798371 .

Publisher's note Springer Nature remains neutral with regard to jurisdictional claims in published maps and institutional affiliations.

\section{Affiliations}

\section{Shereen J. Chaudhry ${ }^{1} \cdot$ Michael Hand $^{2} \cdot$ Howard Kunreuther $^{3}$}

1 University of Chicago Booth School of Business, Chicago, IL 60637, USA

2 U.S. General Services Administration Office of Evaluation Sciences, 1800 F St NW, Washington, DC 20405, USA

3 Department of Operations, Information and Decisions Wharton School, University of Pennsylvania, 3730 Walnut St., \#563 Huntsman Hall, Philadelphia, PA 19104-6340, USA 